Research Article

\title{
Study on Three Sarcocapnos Species as Potential Sources of Bioactive Compounds: Relation between Phenolic Content and Bioactivity by Multivariate Analysis
}

\author{
María del Pilar Fernández-Poyatos, ${ }^{1}$ Gökhan Zengin, ${ }^{2}$ Carlos Salazar-Mendías, ${ }^{3}$ \\ Antonio Ruiz-Medina, ${ }^{1}$ Kouadio Ibrahime Sinan, ${ }^{2}$ and Eulogio J. Llorent-Martínez $\mathbb{B}^{1}$ \\ ${ }^{1}$ Department of Physical and Analytical Chemistry, Faculty of Experimental Sciences, University of Jaén, Campus Las Lagunillas, \\ Jaén E-23071, Spain \\ ${ }^{2}$ Department of Biology, Science Faculty, Selcuk University, Campus, Konya, Turkey \\ ${ }^{3}$ Department of Animal Biology Plant Biology and Ecology, Faculty of Experimental Sciences, University of Jaén, \\ Campus Las Lagunillas, Jaén E-23071, Spain
}

Correspondence should be addressed to Eulogio J. Llorent-Martínez; ellorent@ujaen.es

Received 6 May 2020; Accepted 12 June 2020; Published 11 July 2020

Academic Editor: María José Trujillo Rodríguez

Copyright (C) 2020 María del Pilar Fernández-Poyatos et al. This is an open access article distributed under the Creative Commons Attribution License, which permits unrestricted use, distribution, and reproduction in any medium, provided the original work is properly cited.

\begin{abstract}
In this work, we report the phenolic composition and bioactivity of the aerial parts of three species of Sarcocapnos (S. enneaphylla, S. pulcherrima, and S. saetabensis) to study their potential as sources of bioactive compounds to revalorize them and contribute to the conservation of these plant species. Samples were collected in different locations in the province of Jaén (southeast of Spain), and qualitative and quantitative analyses of phenolic compounds were performed by high-performance liquid chromatography with diode array and mass spectrometry detection. S. enneaphylla presented the highest concentration of phenolic compounds $(58 \mathrm{mg} / \mathrm{g} \mathrm{DE})$. The most abundant compound in $S$. enneaphylla and $S$. saetabensis was rutin $(35 \mathrm{mg} / \mathrm{g} \mathrm{DE}$ and $11.7 \mathrm{mg} / \mathrm{g} \mathrm{DE}$, respectively), whereas isorhamnetin-O-rutinoside was dominant in $S$. pulcherrima $(11.5 \mathrm{mg} / \mathrm{g} \mathrm{DE})$. Several assays were performed to evaluate the potential bioactivity of the three species of Sarcocapnos. These assays included antioxidant and radical scavenging (ABTS and DPPH), reducing power (CUPRAC and FRAP), phosphomolybdenum and metal chelating, and enzyme inhibitory activity (acetylcholinesterase, amylase, butyrylcholinesterase, glucosidase, and tyrosinase). In general, all methanolic extracts presented the highest phenolic and flavonoid contents, as well as the highest radical scavenging, antioxidant, and enzyme inhibitory properties. This relationship between phenolics and bioactivity was confirmed by multivariate analysis.
\end{abstract}

\section{Introduction}

Plants are valuable sources of bioactive compounds of outstanding interest for the pharmaceutical industry. Due to the side effects of synthetic drugs, the interest in natural medicinal plants has increased in the last decade. Phenolic compounds are among the most important phytochemicals of plants due to their important health benefits [1]. The use of natural products is not only exclusive for human health but also for applications in livestock and aquaculture production systems [2]. It is thus important to characterize the composition and bioactivity of phytochemicals in lesserknown plants.

Sarcocapnos DC. (subfam. Fumarioideae, fam. Papaveraceae) is a plant genus endemic to the Western Mediterranean subregion (southwest Europe and northwest Africa) which has been scarcely investigated so far. Papaveraceae plants have been widely used due to their medicinal properties. Among them, several Sarcocapnos species have been consumed as infusions for the treatment of several illnesses. Sarcocapnos genus is composed of ten taxa: seven species and three subspecies [3, 4]. Its main diversification 
center lies in the Iberian Peninsula, from which eight out of the ten accepted taxa are endemic [5]. Except for the northwest African endemism S. crassifolia (Desf.) DC., the rest of the six species are present in Spain. Some of them show a narrow distribution area circumscribed to the Baetic mountains of Southern Iberian Peninsula (Spain), mainly distributed in the area of eastern Andalusia [6].

All Sarcocapnos species are present in overhanging cliffs, mainly over carbonated substrata. Most of them are endangered species [7], usually threatened by their own biological and demographic features, natural processes (droughts and rock collapse), global climate change, and at a lesser extent, by human activities such as quarrying or climbing. Only a few of them are currently protected by law at a national or regional level. Therefore, studies concerning their chemical composition and bioactivity are important to revalorize and to protect these plant species.

The genus Sarcocapnos has proved to be a rich source of isoquinoline alkaloids, most of them with a cularine skeleton [8-10]. However, to our best knowledge, the phenolic composition of Sarcocapnos species has not been reported to date. Also, there are no studies regarding the bioactivity of these plant species. We have therefore studied the phenolic composition and bioactivity of three species (all of them suffruticose chasmophytes) that coexist in the province of Jaén (southeast of Spain): S. enneaphylla, S. pulcherrima, and S. saetabensis.

S. enneaphylla (L.) DC. has the widest distribution area of the genus, from Southern France to Northern Africa, with a great number of populations throughout Spain [11]. Its flowers and leaves show the smallest dimensions of the genus. S. pulcherrima Morales and Romero García is an endemic species to southeastern Spain, with isolated populations in Eastern Andalusia [12]. And finally, S. saetabensis Mateo and Figuerola species seems to have a hybrid origin from S. enneaphylla and S. pulcherrima [13]. It is an endemic species to Eastern Spain from Catalonia to eastern Andalusia. The alkaloid compositions of the three Sarcocapnos species have been previously reported $[8,9,14]$.

Considering the scarce data concerning the mentioned species, the first goal of this work is to detail the composition of the phenolic content of aerial parts of these Sarcocapnos species as well as their antioxidant activity and enzyme inhibitory properties against cholinesterase, amylase, glucosidase, and tyrosinase. The final aim is to develop novel pharmaceutical and food products based on the extracts of these plants (or specific isolated bioactive compounds), therefore valorizing these species as a source of bioactive compounds and hence contributing to their conservation.

\section{Materials and Methods}

All chemicals and reagents are given in File S1 of Supplementary Materials.

2.1. Plant Material and Sample Preparation. Sarcocapnos leaves were collected by hand from different locations (two locations per plant species) in the province of Jaén
(Southeast of Spain) as shown in Table 1. Plant material of each location is a pool of the aerial parts collected from approximately five different plants during the same day. Figure 1 shows the photographs of each Sarcocapnos species in their collection site. The taxonomical classification was confirmed by botanist Dr. Carlos Salazar-Mendías, and voucher numbers are also given in Table 1.

Extractions were carried out in two different media: methanol (MeOH; HPLC grade; Sigma-Aldrich) and water (Milli-Q Waters purification system; Millipore; Milford, MA, USA). Due to the small amount of plant material (most Sarcocapnos species are endangered), we selected $\mathrm{MeOH}$ and water, the most common solvents for the extraction of phenolic compounds. For both extractions, leaves were lyophilized (ModulyoD/23, Thermo Savant; Waltham, MA, USA) and crushed with a grinder.

Methanol extractions were performed as follows: $2.5 \mathrm{~g}$ of dry material was extracted with $50 \mathrm{~mL} \mathrm{MeOH}$ in an ultrasonic liquid processor (Qsonica Sonicators; Newton, CT, USA) with a power of $55 \mathrm{~W}$ and a frequency of $20 \mathrm{kHz}$, for 10 min (using 50\% power) at room temperature. Extractions were done in triplicate. After sonication, solutions were filtered through Whatman No.1 filters. The solvent was evaporated under reduced pressure in a Hei-Vap Precision rotary evaporator (Heidolf; Schwabach, Germany) at $40^{\circ} \mathrm{C}$. Dried extracts (DEs) were stored at $-20^{\circ} \mathrm{C}$ until analysis.

On the other hand, the extractions with water were carried out in the following way: $2.5 \mathrm{~g}$ of dry material was extracted with $150 \mathrm{~mL} \mathrm{H}_{2} \mathrm{O}$ at $100^{\circ} \mathrm{C}$ in a hot plate (C-MAG HS7, IKA; Staufen, Germany) for $30 \mathrm{~min}$. Extractions were done in triplicate. After that, solutions were filtered in a vacuum pump (Vacuubrand; Wertheim, Germany) through Whatman No. 1 filters. Finally, the solvent was evaporated under reduced pressure, and the dried extracts were stored at $-20^{\circ} \mathrm{C}$ until analysis.

2.2. HPLC Analysis of the Phenolic Compounds. The extracts were analyzed with high-performance liquid chromatography with diode-array and mass spectrometry detection (HPLC-DAD-MS ${ }^{\mathrm{n}}$ ), operating in both negative and positive ion modes. Instrumentation and detailed conditions are given in File S2 of Supplementary Materials.

Five milligrams of DE $(\mathrm{MeOH})$ was redissolved in $1 \mathrm{~mL}$ of $\mathrm{MeOH}$, and $5 \mathrm{mg}$ of $\mathrm{DE}\left(\mathrm{H}_{2} \mathrm{O}\right)$ was redissolved in $1 \mathrm{~mL}$ of $\mathrm{MeOH}: \mathrm{H}_{2} \mathrm{O}(10: 90 ; \mathrm{v}: \mathrm{v})$. After filtration through $0.45 \mu \mathrm{m}$ nylon membrane filters for methanolic extracts and $0.45 \mu \mathrm{m}$ PVDF membrane filters for aqueous extracts, $10 \mu \mathrm{L}$ of sample were injected.

Individual sock solutions of caffeic acid, neochlorogenic acid, coumaric acid, ferulic acid, hydroxytyrosol, sinapic acid, quercetin, kaempferol, and rutin were prepared in $\mathrm{MeOH}$. We prepared calibration curves for caffeic acid, neochlorogenic acid, coumaric acid, ferulic acid, hydroxytyrosol, sinapic acid, quercetin, and rutin at concentrations $0.5-100 \mu \mathrm{g} \mathrm{mL}^{-1}$ in $\mathrm{MeOH}$. Chromatograms were recorded at $280 \mathrm{~nm}$ for hydroxytyrosol; $320 \mathrm{~nm}$ for caffeic acid, neochlorogenic acid, coumaric acid, ferulic acid, and sinapic acid; and $350 \mathrm{~nm}$ for quercetin and rutin. Peak area (at the 
TABLE 1: Sarcocapnos species collected and their location.

\begin{tabular}{|c|c|c|c|c|}
\hline Sarcocapnos species & Sample & Location & $\begin{array}{c}\text { Geographical coordinates/altitude } \\
\text { (m a.s.l.) }\end{array}$ & Herbarium sheet \\
\hline \multirow{2}{*}{ S. enneaphylla } & SE1 & Alcaudete (Jaén, Spain) & $37^{\circ} 36^{\prime} 5.39^{\prime \prime} \mathrm{N} 4^{\circ} 2^{\prime} 56.57^{\prime \prime} \mathrm{W} / 891$ & 65532 \\
\hline & SE2 & Vilches (Jaén, Spain) & $38^{\circ} 12^{\prime} 52.4^{\prime \prime} \mathrm{N}^{\circ} 28^{\prime} 53.8^{\prime \prime} \mathrm{W} / 690$ & GDA \\
\hline \multirow{2}{*}{ S. pulcherrima } & SP1 & Fuensanta de Martos (Jaén, Spain) & $37^{\circ} 38^{\prime} 59.6^{\prime \prime} \mathrm{N} 3^{\circ} 53^{\prime} 57.9^{\prime \prime} \mathrm{W} / 796$ & GDA 65529, GDA 65530 \\
\hline & SP2 & Jódar (Jaén, & $37^{\circ} 48^{\prime} 47.9^{\prime \prime} \mathrm{N} 3^{\circ} 20^{\prime} 59.9^{\prime \prime} \mathrm{W} / 1020$ & GDA 65531 \\
\hline \multirow{2}{*}{ S. saetabensis } & SS1 & Between Jaén and Otíñar (Jaén & $37^{\circ} 41^{\prime} 28.3^{\prime \prime} \mathrm{N} 3^{\circ} 45^{\prime} 46.2^{\prime \prime} \mathrm{W} / 606$ & GDA 65536 \\
\hline & SS2 & Segura de la Sierra (Jaén, Spain) & $38^{\circ} 17^{\prime} 54.9^{\prime \prime} \mathrm{N} 2^{\circ} 39^{\prime} 00.6^{\prime \prime} \mathrm{W} / 1202$ & GDA 65541, GDA 65542 \\
\hline
\end{tabular}

m.a.s.l.: metres above sea level; GDA: Herbarium of the University of Granada.

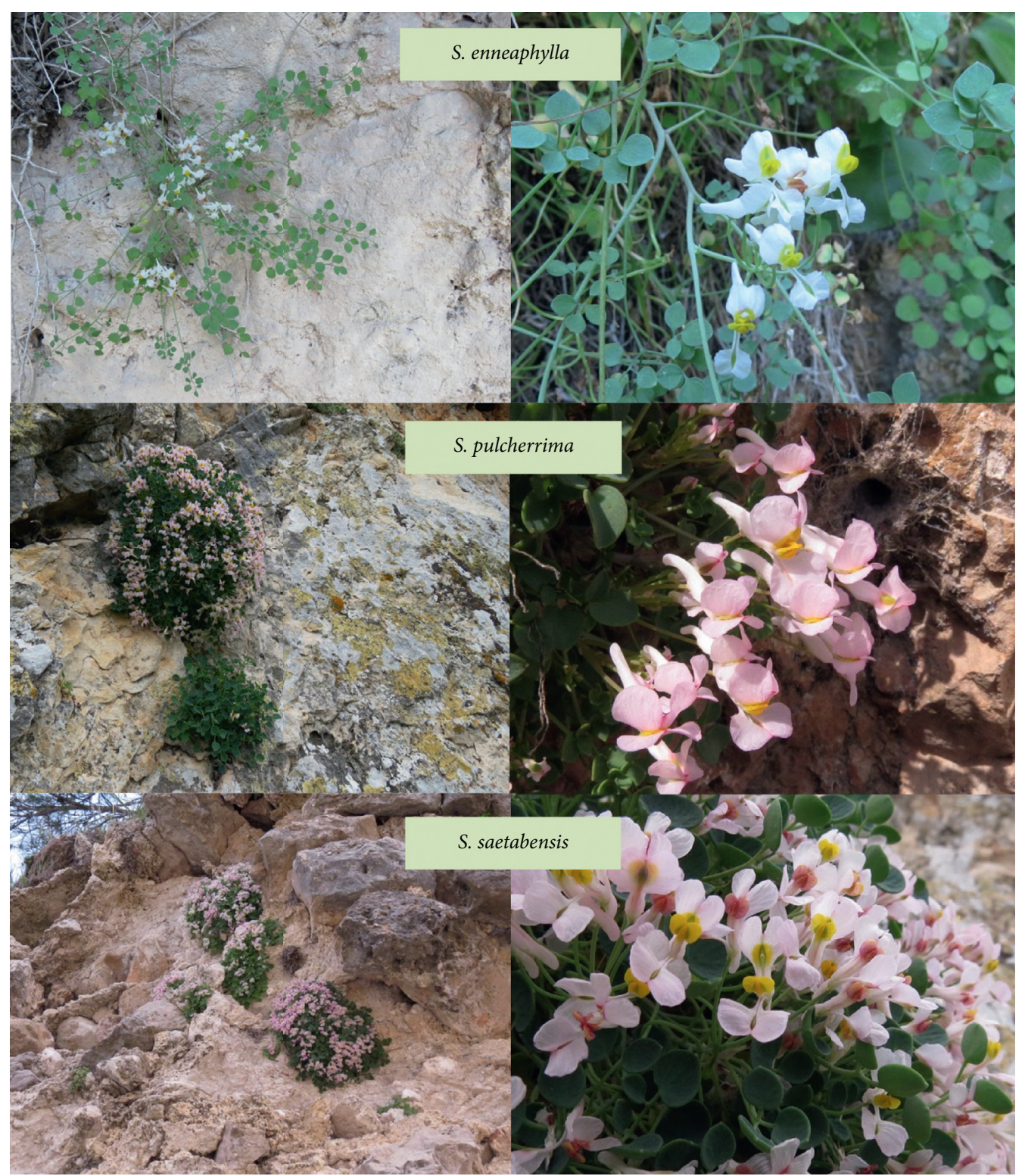

Figure 1: Photographs of S. enneaphylla, S. pulcherrima, and S. saetabensis.

corresponding wavelength) was plotted vs analyte concentration to construct the calibration graphs. Repeatability $(n=9)$ and intermediate precision ( $n=9,3$ consecutive days) were lower than 3 and $8 \%$, respectively. The robustness of the method was assessed by measuring signals at $\pm 2 \mathrm{~nm}$ of the optimum wavelength and by modifying the percentage of mobile phases $(2 \%$ variation with respect to optimum conditions), observing variations lower than $5 \%$ in all cases. 
2.3. Assays for Total Phenolic and Flavonoid Contents. Total phenolic content (TPC) and total flavonoid content (TFC) were measured by spectrophotometric assays [15]. The obtained results were reported as standard equivalents of gallic acid and rutin for phenolics and flavonoids, respectively. Details for the protocols are provided in File S3 of Supplementary Materials.

\subsection{Determination of Antioxidant and Enzyme Inhibitory} Effects. Regarding the antioxidant activity of Sarcocapnos extracts, different spectrophotometric assays were performed: ferrous ion chelating, phosphomolybdenum, FRAP, ABTS, CUPRAC, and DPPH [15]. Results are given as standard compounds equivalents of Trolox and EDTA. Details are given in File S4 of Supplementary Materials.

The in vitro enzyme inhibitory effects of Sarcocapnos extracts were evaluated on five enzymes: $\alpha$-amylase, $\alpha$-glucosidase, acetyl- and butyryl-cholinesterases, and tyrosinase. The enzyme inhibitory actions were assessed as kojic acid equivalents (KAE) for tyrosinase, galantamine equivalents (GALAE) for acetylcholinesterase (AChE) and butyrylcholinesterase (BChE), and acarbose equivalents (ACAE) for $\alpha$-amylase and $\alpha$-glucosidase. Assays were performed as previously reported $[15,16]$, and the details for the protocols are provided in File S4 of Supplementary Materials.

2.5. Statistical Analysis. The different Sarcocapnos extracts were analyzed in triplicate (there were 3 independent extracts for each plant species; Section 2.1), and the values were given as mean $\pm S D$. Firstly, the data were submitted to a descriptive analysis (ANOVA one-way) followed by Tukey's test, using XLSTAT v.2018 (Addinsoft Inc) statistical software. A significance level of $5 \%$ was set for all analyses. Unsupervised principal component analysis (PCA) was performed in order to investigate similarities/differences between different samples and to identify the factors responsible for the distinguishing between that samples. Prior to principal component analysis, data were prepreprocessed (autoscaling). Afterwards, Hierarchical Cluster Analysis (HCA) was applied on the results of PCA to bring out the different clusters. To this end, the Euclidean similarity measure and complete linkage were chosen. Finally, Pearson's correlation was carried out to assess the relationship between total bioactive compounds and biological activities. All statistics were done under R v.3.6.1 software.

\section{Results and Discussion}

3.1. HPLC-MS Analysis. Mass spectrometry was used for compounds characterization. A typical chromatogram is shown in Figure S1 of Supplementary Materials. We identified or tentatively characterized 37 compounds, of which more than $30 \%$ corresponded to flavonoids and more than $40 \%$ were phenolic acids. The characterization of the compounds was performed by using information available in scientific literature and the use of analytical standards. Compounds were numbered according to their order of elution (Table 2), maintaining the same numeration in all samples.

3.1.1. Flavonoids. Compounds 12, 21, 27, and 30 were identified as quercetin-O-glycosides. All of them displayed neutral losses of 146,162 , and $308 \mathrm{Da}$, which corresponded to deoxyhexoside, hexoside, and rutinoside moieties. The presence of quercetin was confirmed by the fragment ions at $\mathrm{m} / \mathrm{z} 301,179$, and 151 (comparison with an analytical standard). The identity of rutin (compound 27 was confirmed by comparison with an analytical standard).

Compounds 17, 25, 34, 35, 36, and 38 were isorhamnetin-O-glycosides. They were also characterized by the neutral losses previously mentioned, as well as the loss of acetylhexoside (204 Da) in compound 38. In all of them, the aglycone isorhamnetin was observed at $\mathrm{m} / z 315$ (typical fragment at $\mathrm{m} / \mathrm{z} 300$; comparison with an analytical standard).

Compounds 31 and 33 were putatively characterized as kaempferol-O-rutinoside isomers due to the loss of rutinoside (308 Da) and the presence of the aglycone kaempferol at $m / z 285$ (the aglycone was identified as kaempferol due to the absence of $\mathrm{MS}^{3}$ fragment ions at $m / z 243$ and 241, which would be indicative of luteolin; analytical standards of both kaempferol and luteolin were analyzed).

3.1.2. Phenolic Acids. Compounds 3, 11, 16, 20, 22, and 24 were characterized as feruloylquinic acid isomers. Compounds 3 and $\mathbf{1 1}$ displayed deprotonated molecular ions at $\mathrm{m} / z 367$ with $\mathrm{MS}^{2}$ and $\mathrm{MS}^{3}$ base peaks at $m / z 193$ and 134, respectively; they were identified as 3 -feruloylquinic acid isomers [17]. Compounds 16 and 20 presented $[\mathrm{M}-\mathrm{H}]^{-}$ion at $m / z 367$, with $\mathrm{MS}^{2}$ and $\mathrm{MS}^{3}$ base peaks at $m / z 173$ and 111 , respectively; they were characterized as 4 -feruloylquinic acid isomers [17]. Compounds 22 and 24, with $[\mathrm{M}-\mathrm{H}]^{-}$ion at $m / z 367$ and MS $^{2}$ base peak at $m / z$ 191, were characterized as 5 -feruloylquinic acid isomers [17].

Compound 8 with $[\mathrm{M}-\mathrm{H}]^{-}$ion at $\mathrm{m} / z 353$ presented fragment ions at $m / z 191$ and 179 , which corresponded to neochlorogenic acid (identified by comparison with an analytical standard).

Compounds 9 and $\mathbf{1 0}$ were characterized as 3-p-coumaroylquinic acid isomers based on the $[\mathrm{M}-\mathrm{H}]^{-}$ions at $\mathrm{m} / \mathrm{z}$ 337, $\mathrm{MS}^{2}$ base peak at $m / z 163$, and comparison of their fragmentation pattern with bibliographic data [17].

Compound 14 was characterized as ferulic acid glucuronide; it exhibited deprotonated molecular ion at $\mathrm{m} / \mathrm{z} 369$ and suffered the neutral loss of $176 \mathrm{Da}$ (glucuronide) to yield fragment ions at $\mathrm{m} / \mathrm{z} 193$ and 134, typical of ferulic acid. Compound $\mathbf{2 8}$ corresponded to ferulic acid (identified by comparison with an analytical standard).

Compound 19, $[\mathrm{M}-\mathrm{H}]^{-}$at $\mathrm{m} / z 295$, had major fragments at $\mathrm{m} / z 179$ and 135 , which indicated the presence of caffeic acid; it was characterized as caffeic acid cinnamyl ester [18].

Compound 23 presented $[\mathrm{M}-\mathrm{H}+\mathrm{HCOOH}]^{-}$at $\mathrm{m} / z$ 453 and was tentatively identified as coumaric acid-Ohexoside derivative (formate adduct) due to the neutral loss of hexoside $(325 \longrightarrow 163)$ and the presence of coumaric acid 
TABLE 2: Characterization of the compounds found in the analyzed extracts of Sarcocapnos species by HPLC-DAD/ESI-MS ${ }^{\mathrm{n}}$, in methanolic $(\mathrm{M})$ and aqueous $(\mathrm{W})$ media.

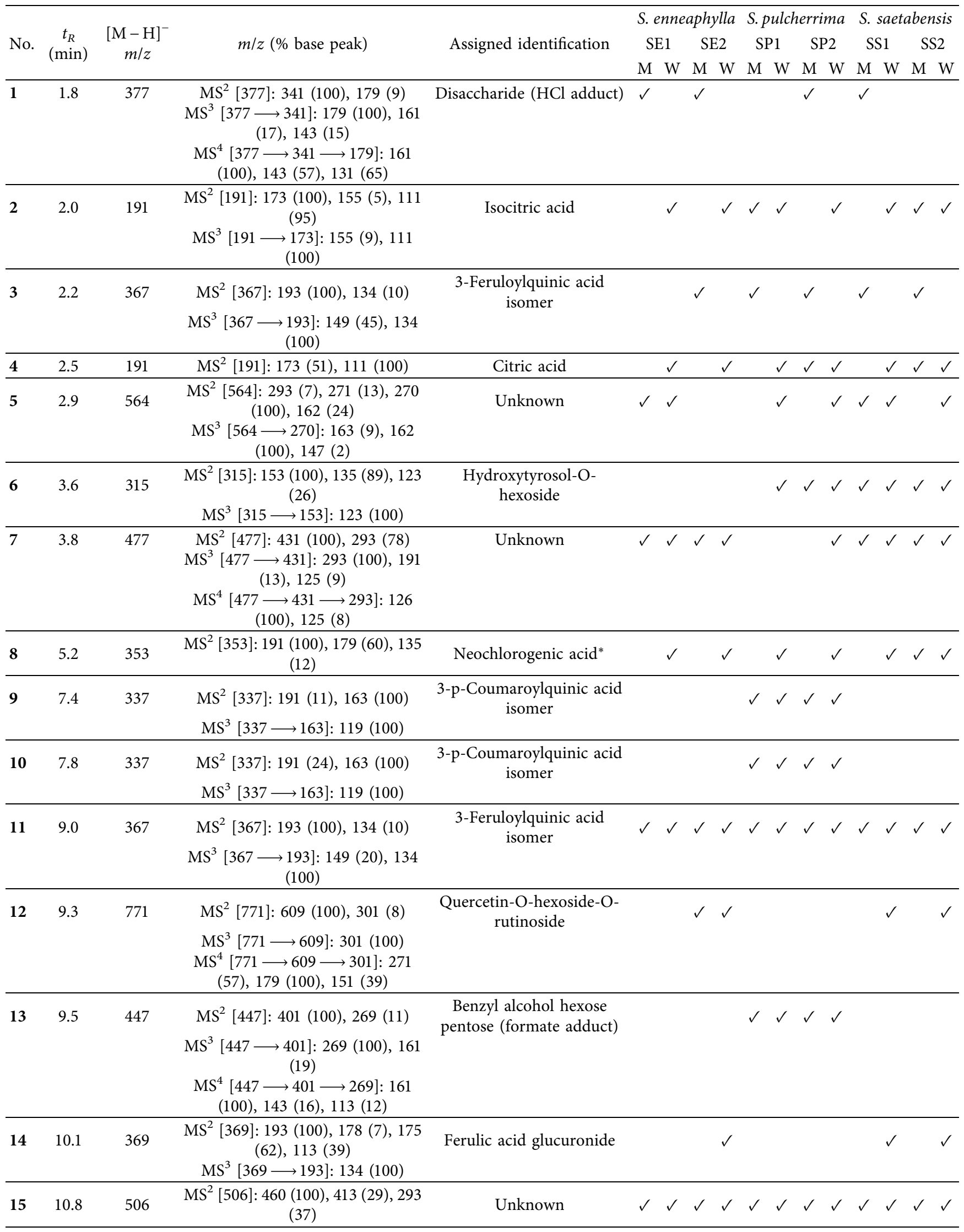


TABle 2: Continued.

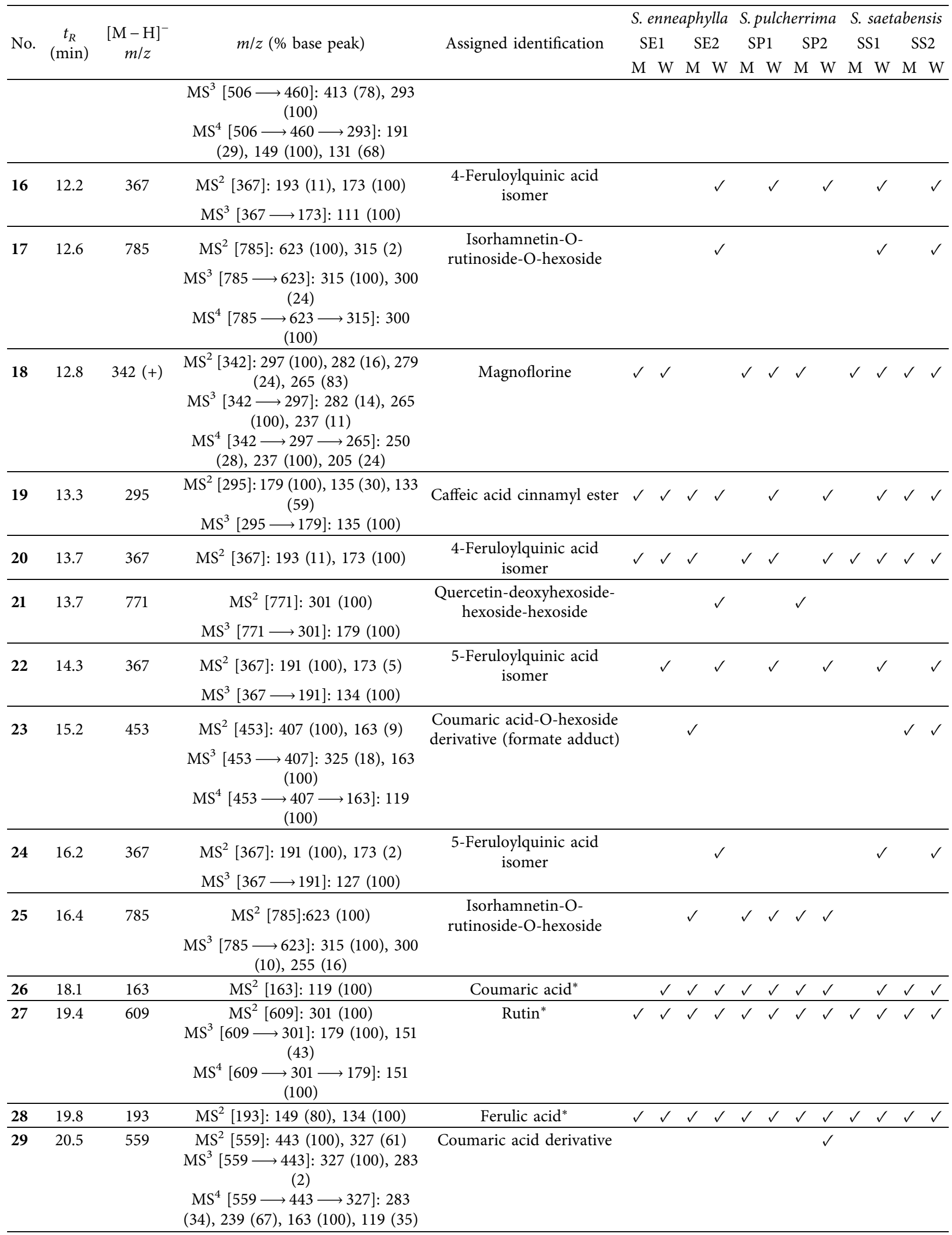


TABLE 2: Continued.

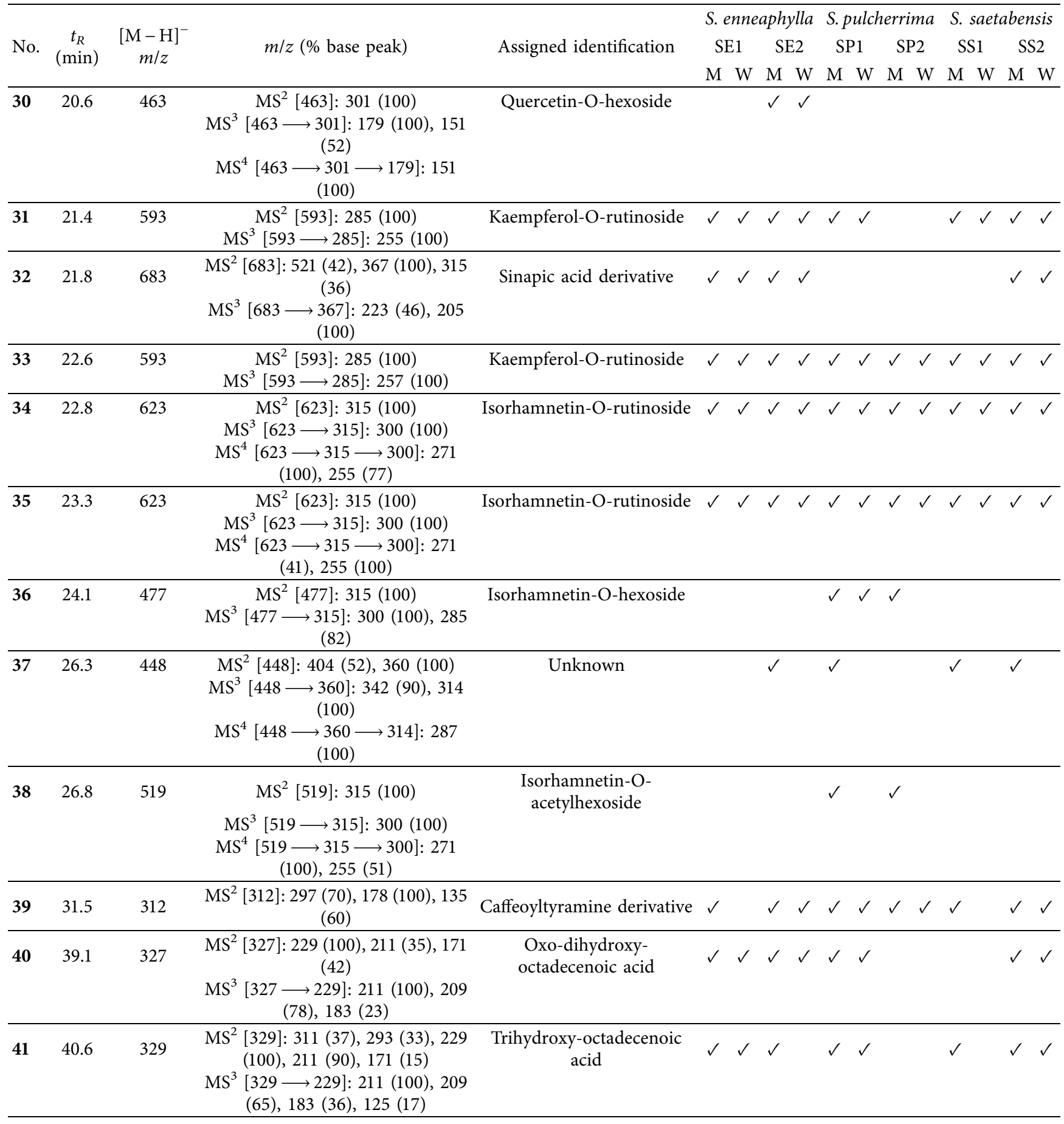

${ }^{*}$ Identified with analytical standards.

(fragmentation $163 \longrightarrow 119$ ). Compound 26 was identified as coumaric acid by comparison with an analytical standard. Compound 29 was tentatively characterized as a coumaric acid derivative.

Compound 32 displayed deprotonated molecular ion at $m / z 683$, with fragments at $m / z 223$ and $m / z 205$, typical of the sinapic acid fragmentation, so this compound was tentatively identified as sinapic acid derivative.
3.1.3. Other Compounds. Compound $\mathbf{1}$ was identified as a disaccharide ( $\mathrm{HCl}$ adduct) formed by two hexosides $(\mathrm{m} / z$ 341). The fragment ions at $\mathrm{m} / z 179$ and 161 are typical from hexoside moieties.

Compounds $\mathbf{2}$ and $\mathbf{4}$ were characterized as isocitric acid and citric acid, respectively. Both showed $[\mathrm{M}-\mathrm{H}]^{-}$ion at $\mathrm{m} / z$ 191, but citric acid exhibited two fragment ions at $\mathrm{m} / z$ 111 (base peak) and $m / z 173$, while isocitric acid showed 
fragment ions at $m / z 173$ (base peak), $m / z 155$, and $m / z 111$ [19].

Compound 6 presented $[\mathrm{M}-\mathrm{H}]^{-}$ion at $m / z 315$ and suffered the neutral loss of a hexoside moiety (162 Da), obtaining the typical fragmentation of hydroxytyrosol $(\mathrm{m} / \mathrm{z}$ 153,135 , and 123). This compound was named as hydroxytyrosol-O-hexoside [20].

Compound 13 was identified as benzyl alcohol hexose pentose (formate adduct) with $[\mathrm{M}-\mathrm{H}]^{-}$ion at $m / z 447$ and fragments at $m / z 401$ (neutral loss of $\mathrm{HCl}$ ), $m / z 269$ (neutral loss of pentoside molecule, $132 \mathrm{Da}$ ), and $\mathrm{m} / z 161$ (neutral loss of benzyl alcohol, $108 \mathrm{Da}$ ) corresponding with a hexoside [21].

Compound $18(\mathrm{~m} / z$ 342) was characterized as magnoflorine using the positive ion mode. This alkaloid presented the base peak at $m / z 297$, and other fragment ions at $m / z 282$ and 265 [22].

Compound 39, with $[\mathrm{M}-\mathrm{H}]^{-}$ion at $m / z$ 312, presented fragment ions at $m / z 297,178$, and 135, typical of caffeoyltyramine derivative [23].

Compounds $\mathbf{4 0}$ and $\mathbf{4 1}$ were identified as oxo-dihydroxyoctadecenoic acid (oxo-DHODE) and trihydroxy-octadecenoic acid (THODE), respectively, based on bibliographic data [24].

3.2. Quantification of Phenolic Compounds. Twenty-seven compounds were quantified in the analyzed extracts of S. enneaphylla, S. pulcherrima, and S. saetabensis by HPLCDAD using analytical standards of the corresponding chemical families.

In the three Sarcocapnos species under study, methanolic extracts always presented the highest concentration of phytochemicals, mainly due to the higher solubility of flavonoids in methanol than water. In addition, it implies that methanol is more efficient in cells walls degradation of Sarcocapnos species, probably due to their nonpolar character. Quantification data of all the extracts of Sarcocapnos are given in Tables 3-5.

Total individual phenolic content (TIPC) was defined as the sum of all the compounds quantified individually by HPLC-DAD. TIPC data are shown in Tables 3-5 as well as in Figure S2 of Supplementary Materials. It can be observed that the TIPC values were in the following order: $S$. enneaphylla $>$ S. pulcherrima $>$ S. saetabensis. This pattern is in agreement with flavonoids concentrations in the three Sarcocapnos species.

All extracts had a higher concentration of flavonoids than phenolic acids, except the aqueous extracts of $S$. saetabensis, in which phenolic acids were more abundant. This was due to the presence of compound 19 (caffeic acid cinnamyl ester), which was the dominant phenolic acid. Flavonoids represented a contribution to TIPC of $84-86 \%$ (methanol extract) and 53-68\% (aqueous extract) in $S$. enneaphylla. For S. pulcherrima, flavonoids contribution to TIPC was $87 \%$ (methanol extract) and 53-61\% (aqueous extract). Finally, for S. saetabensis, flavonoids contributions to TIPC were $67-77 \%$ and $43-46 \%$ for the methanol and aqueous extracts, respectively.
The two main flavonoids in all extracts were rutin and isorhamnetin-O-rutinoside. In the methanolic extracts of $S$. enneaphylla, both flavonoids represented $81-93 \%$ of the concentration of all flavonoids $(80-84 \%$ in the aqueous extracts). In S. pulcherrima, these two flavonoids represented $61-63 \%$ and $65-81 \%$ of all flavonoids in the methanol and aqueous extracts, respectively. Finally, in S. saetabensis, rutin and isorhamnetin-O-rutinoside accounted for $82-84 \%$ and $74-81 \%$ of all flavonoids in the methanolic and aqueous extracts, respectively.

The main phenolic acids were 3-feruloylquinic acid isomers, caffeic acid cinnamyl ester, and coumaric acid. These three compounds accounted for the following percentages of TIPC: $74-80 \%$ (methanol extract) and 68-70\% (aqueous extract) in S. enneaphylla, 74-75\% (methanol extract) and 59-60\% (aqueous extract) in S. pulcherrima, and 54-84\% (methanol extract) and 55-56\% (aqueous extract) in S. saetabensis.

3.3. Total Phenolic and Flavonoid Contents. The total phenolic and flavonoid contents of the Sarcocapnos extracts are illustrated in Figure 2 (also in Table S1 of Supplementary Materials). The highest total phenolic content was determined in $S$. enneaphylla $(61.2 \mathrm{mg} \mathrm{GAE} / \mathrm{g})$, followed by $S$. saetabensis (50.6 mg GAE/g) and S. pulcherrima (43.8 mg GAE/g). Regarding the total flavonoid content, the trend was similar to the one for total phenolic content. This finding is consistent with the HPLC-DAD quantification results, which indicated the highest levels of phenolics and flavonoids (particularly rutin) in $S$. enneaphylla methanol extracts. As can be seen in Figure S3 of Supplementary Materials, the levels of total bioactive compounds exhibited significant differences for each Sarcocapnos species in terms of location. This fact was also mentioned by several authors who reported that the amounts of bioactive compounds could vary due to climatic of geographical conditions [25-27]. Besides, methanol has proved to be the best solvent for the extraction of phenolics and flavonoids from Sarcocapnos species. In earlier studies [28, 29], the effects of solvents on total bioactive compounds were investigated, and methanol was also found to be the most effective for most of them, in agreement with our findings. Based on our information, there are no previous studies concerning the total amount of bioactive compounds in the genus Sarcocapnos. In this sense, these results will be a scientific starting point on this genus.

3.4. Antioxidant Ability. The antioxidant abilities of the Sarcocapnos species are shown in Table 6 and are expressed in terms of standard equivalents (trolox (TE) and EDTA (EDTAE)). We used antioxidant assays involving different mechanisms (metal chelating, radical quenching, and reduction ability). Similar to the levels of total bioactive compounds, antioxidant activities changed in terms of location in each species. Except for metal chelating ability, the tested methanol extracts exhibited stronger antioxidant abilities when compared with water 
TABLE 3: Quantification of compounds in extracts of S. enneaphylla (SE) from two different locations, extracted in methanol and water.

\begin{tabular}{|c|c|c|c|c|c|}
\hline & \multirow{3}{*}{ Compound } & \multicolumn{4}{|c|}{ S. enneaphylla } \\
\hline & & \multicolumn{2}{|c|}{$\mathrm{MeOH}$} & \multicolumn{2}{|c|}{$\mathrm{H}_{2} \mathrm{O}$} \\
\hline & & SE1 & SE2 & SE1 & SE2 \\
\hline \multicolumn{6}{|l|}{ Flavonoids } \\
\hline 12 & Quercetin-O-hexoside-O-rutinoside & - & $0.39 \pm 0.02$ & - & $0.93 \pm 0.05$ \\
\hline 17 & Isorhamnetin-O-rutinoside-O-hexoside & - & - & - & $0.28 \pm 0.01$ \\
\hline 21 & Quercetin-deoxyhexoside-hexoside-hexoside & - & - & - & $1.11 \pm 0.06$ \\
\hline 25 & Isorhamnetin-O-rutinoside-O-hexoside & - & $0.28 \pm 0.01$ & - & - \\
\hline 27 & Rutin & $14.7 \pm 0.7$ & $35 \pm 2$ & $4.4 \pm 0.2$ & $10.5 \pm 0.4$ \\
\hline 30 & Quercetin-O-hexoside & - & $0.36 \pm 0.02$ & - & $0.15 \pm 0.01$ \\
\hline 31 & Kaempferol-O-rutinoside & $0.87 \pm 0.04$ & $0.30 \pm 0.02$ & $0.27 \pm 0.01$ & $0.15 \pm 0.01$ \\
\hline $33+34$ & Kaempferol-O-rutinoside + Isorhamnetin-O-rutinoside & $5.4 \pm 0.2$ & $2.5 \pm 0.1$ & $1.18 \pm 0.05$ & $0.66 \pm 0.03$ \\
\hline 35 & Isorhamnetin-O-rutinoside & $12.6 \pm 0.5$ & $10.5 \pm 0.5$ & $3.2 \pm 0.2$ & $2.9 \pm 0.2$ \\
\hline Total & & $33.6 \pm 0.9$ & $49 \pm 2$ & $9.1 \pm 0.3$ & $16.7 \pm 0.5$ \\
\hline \multicolumn{6}{|c|}{ Phenolic acids } \\
\hline 3 & 3-Feruloylquinic acid isomer & - & $0.70 \pm 0.04$ & - & - \\
\hline 8 & Neochlorogenic acid & - & - & $0.47 \pm 0.02$ & $0.61 \pm 0.03$ \\
\hline 11 & 3-Feruloylquinic acid isomer & $3.0 \pm 0.1$ & $4.9 \pm 0.2$ & $0.92 \pm 0.05$ & $1.53 \pm 0.08$ \\
\hline 14 & Ferulic acid glucuronide & - & - & - & $0.080 \pm 0.003$ \\
\hline 16 & 4-Feruloylquinic acid isomer & - & - & - & $0.14 \pm 0.01$ \\
\hline 19 & Caffeic acid cinnamyl ester & $1.32 \pm 0.04$ & $1.78 \pm 0.08$ & $4.25 \pm 0.2$ & $3.7 \pm 0.2$ \\
\hline 20 & 4-Feruloylquinic acid isomer & $0.20 \pm 0.01$ & $0.74 \pm 0.03$ & $0.56 \pm 0.03$ & - \\
\hline 22 & 5-Feruloylquinic acid isomer & - & - & $0.42 \pm 0.02$ & $0.46 \pm 0.03$ \\
\hline 24 & 5-Feruloylquinic acid isomer & - & - & - & $0.10 \pm 0.01$ \\
\hline 26 & Coumaric acid & - & $0.22 \pm 0.01$ & $0.37 \pm 0.02$ & $0.27 \pm 0.01$ \\
\hline 28 & Ferulic acid & $0.74 \pm 0.04$ & $0.83 \pm 0.04$ & $0.99 \pm 0.05$ & $0.94 \pm 0.05$ \\
\hline 32 & Sinapic acid derivative & $0.160 \pm 0.007$ & $0.120 \pm 0.06$ & $0.13 \pm 0.01$ & $0.100 \pm 0.008$ \\
\hline Total & & $5.4 \pm 0.1$ & $9.3 \pm 0.2$ & $8.1 \pm 0.2$ & $7.9 \pm 0.2$ \\
\hline TIPC & & $39.0 \pm 0.9$ & $58 \pm 2$ & $17.2 \pm 0.4$ & $24.6 \pm 0.5$ \\
\hline
\end{tabular}

Values (mg/g DE) are mean \pm SD of three parallel measurements. TIPC: total individual phenolic content.

TABLE 4: Quantification of compounds in extracts of S. pulcherrima (SP) from two different locations, extracted in methanol and water.

\begin{tabular}{|c|c|c|c|c|c|}
\hline \multirow{3}{*}{\multicolumn{2}{|c|}{ Compound }} & \multicolumn{4}{|c|}{ S. pulcherrima } \\
\hline & & \multicolumn{2}{|c|}{$\mathrm{MeOH}$} & \multicolumn{2}{|c|}{$\mathrm{H}_{2} \mathrm{O}$} \\
\hline & & SP1 & SP2 & SP1 & SP2 \\
\hline \multicolumn{6}{|l|}{ Flavonoids } \\
\hline 21 & Quercetin-deoxyhexoside-hexoside-hexoside & - & $0.77 \pm 0.03$ & - & - \\
\hline 25 & Isorhamnetin-O-rutinoside-O-hexoside & $0.39 \pm 0.02$ & $0.97 \pm 0.05$ & $0.35 \pm 0.02$ & $0.85 \pm 0.05$ \\
\hline 27 & Rutin & $6.9 \pm 0.3$ & $4.3 \pm 0.2$ & $3.5 \pm 0.2$ & $2.0 \pm 0.1$ \\
\hline 31 & Kaempferol-O-rutinoside & $0.62 \pm 0.03$ & - & $0.31 \pm 0.01$ & - \\
\hline $33+34$ & Kaempferol-O-rutinoside + Isorhamnetin-O-rutinoside & $9.4 \pm 0.5$ & $5.1 \pm 0.3$ & $1.17 \pm 0.07$ & $1.56 \pm 0.07$ \\
\hline 35 & Isorhamnetin-O-rutinoside & $11.5 \pm 0.6$ & $6.8 \pm 0.4$ & $5.1 \pm 0.2$ & $2.5 \pm 0.1$ \\
\hline 36 & Isorhamnetin-O-hexoside & $0.30 \pm 0.02$ & $0.15 \pm 0.01$ & $0.16 \pm 0.01$ & - \\
\hline 38 & Isorhamnetin-O-acetylhexoside & $0.23 \pm 0.01$ & $0.17 \pm 0.02$ & - & - \\
\hline Total & & $29.3 \pm 0.8$ & $18.3 \pm 0.5$ & $10.6 \pm 0.3$ & $6.9 \pm 0.2$ \\
\hline \multicolumn{6}{|c|}{ Phenolic acids } \\
\hline 3 & 3-Feruloylquinic acid isomer & $0.18 \pm 0.01$ & $0.12 \pm 0.01$ & - & - \\
\hline 8 & Neochlorogenic acid & - & - & $0.37 \pm 0.02$ & $0.37 \pm 0.02$ \\
\hline 9 & 3-p-Coumaroylquinic acid isomer & $0.18 \pm 0.01$ & $0.15 \pm 0.01$ & $0.13 \pm 0.01$ & $0.13 \pm 0.01$ \\
\hline 10 & 3-p-Coumaroylquinic acid isomer & $0.27 \pm 0.02$ & $0.22 \pm 0.01$ & $0.19 \pm 0.01$ & $0.19 \pm 0.02$ \\
\hline 11 & 3-Feruloylquinic acid isomer & $2.0 \pm 0.2$ & $1.4 \pm 0.05$ & $1.07 \pm 0.06$ & $0.84 \pm 0.04$ \\
\hline 16 & 4-Feruloylquinic acid isomer & - & - & $0.23 \pm 0.02$ & $0.20 \pm 0.01$ \\
\hline 19 & Caffeic acid cinnamyl ester & - & - & $0.83 \pm 0.04$ & $0.94 \pm 0.04$ \\
\hline 20 & 4-Feruloylquinic acid isomer & $0.22 \pm 0.01$ & - & $0.82 \pm 0.03$ & $0.76 \pm 0.03$ \\
\hline 22 & 5-Feruloylquinic acid isomer & - & - & $0.33 \pm 0.02$ & $0.21 \pm 0.01$ \\
\hline 26 & Coumaric acid & $1.27 \pm 0.05$ & $0.66 \pm 0.04$ & $1.91 \pm 0.08$ & $1.75 \pm 0.09$ \\
\hline 28 & Ferulic acid & $0.28 \pm 0.01$ & $0.18 \pm 0.01$ & $0.61 \pm 0.03$ & $0.50 \pm 0.03$ \\
\hline Total & & $4.4 \pm 0.2$ & $2.73 \pm 0.07$ & $6.5 \pm 0.1$ & $5.9 \pm 0.1$ \\
\hline \multicolumn{6}{|c|}{ Other compounds } \\
\hline 6 & Hydroxytyrosol-O-hexoside & - & $0.090 \pm 0.004$ & $0.100 \pm 0.003$ & $0.080 \pm 0.003$ \\
\hline TIPC & & $33.7 \pm 0.8$ & $21.1 \pm 0.5$ & $17.2 \pm 0.3$ & $12.9 \pm 0.2$ \\
\hline
\end{tabular}

Values (mg/g DE) are mean \pm SD of three parallel measurements. TIPC: total individual phenolic content. 
TABLE 5: Quantification of compounds in extracts of S. saetabensis (SS) from two different locations, extracted in methanol and water.

\begin{tabular}{|c|c|c|c|c|c|}
\hline & \multirow{3}{*}{ Compound } & \multicolumn{4}{|c|}{ S. saetabensis } \\
\hline & & \multicolumn{2}{|c|}{$\mathrm{MeOH}$} & \multicolumn{2}{|c|}{$\mathrm{H}_{2} \mathrm{O}$} \\
\hline & & SS1 & SS2 & SS1 & SS2 \\
\hline \multicolumn{6}{|l|}{ Flavonoids } \\
\hline 12 & Quercetin-O-hexoside-O-rutinoside & - & - & $0.46 \pm 0.02$ & $0.35 \pm 0.02$ \\
\hline 17 & Isorhamnetin-O-rutinoside-O-hexoside & - & - & $0.21 \pm 0.01$ & $0.31 \pm 0.01$ \\
\hline 27 & Rutin & $11.7 \pm 0.5$ & $8.9 \pm 0.4$ & $3.59 \pm 0.02$ & $4.5 \pm 0.3$ \\
\hline 31 & Kaempferol-O-rutinoside & $0.60 \pm 0.03$ & $0.32 \pm 0.02$ & $0.20 \pm 0.01$ & $0.20 \pm 0.01$ \\
\hline $33+34$ & $\begin{array}{c}\text { Kaempferol-O-rutinoside + Isorhamnetin- } \\
\text { O-rutinoside }\end{array}$ & $2.8 \pm 0.1$ & $2.84 \pm 0.01$ & $0.75 \pm 0.04$ & $1.16 \pm 0.05$ \\
\hline 35 & Isorhamnetin-O-rutinoside & $3.5 \pm 0.2$ & $8.4 \pm 0.4$ & $1.03 \pm 0.04$ & $3.9 \pm 0.2$ \\
\hline Total & & $18.6 \pm 0.5$ & $20.5 \pm 0.6$ & $6.24 \pm 0.06$ & $10.4 \pm 0.4$ \\
\hline \multicolumn{6}{|c|}{ Phenolic acids } \\
\hline 3 & 3-Feruloylquinic acid isomer & - & $1.01 \pm 0.06$ & - & - \\
\hline 8 & Neochlorogenic acid & - & $2.5 \pm 0.2$ & $0.78 \pm 0.04$ & $2.1 \pm 0.1$ \\
\hline 11 & 3-Feruloylquinic acid isomer & $4.1 \pm 0.2$ & $3.5 \pm 0.2$ & $1.51 \pm 0.07$ & $2.1 \pm 0.1$ \\
\hline 14 & Ferulic acid glucuronide & - & - & $0.100 \pm 0.006$ & $0.10 \pm 0.01$ \\
\hline 16 & 4-Feruloylquinic acid isomer & - & - & $0.20 \pm 0.01$ & $0.27 \pm 0.02$ \\
\hline 19 & Caffeic acid cinnamyl ester & - & $1.38 \pm 0.05$ & $2.7 \pm 0.2$ & $4.0 \pm 0.2$ \\
\hline 20 & 4-Feruloylquinic acid isomer & $0.19 \pm 0.01$ & $0.24 \pm 0.01$ & $1.00 \pm 0.04$ & $1.06 \pm 0.03$ \\
\hline 22 & 5-Feruloylquinic acid isomer & - & - & $0.50 \pm 0.03$ & $0.56 \pm 0.03$ \\
\hline 24 & 5-Feruloylquinic acid isomer & - & - & $0.090 \pm 0.004$ & $0.090 \pm 0.004$ \\
\hline 26 & Coumaric acid & - & $0.32 \pm 0.01$ & $0.26 \pm 0.01$ & $0.43 \pm 0.02$ \\
\hline 28 & Ferulic acid & $0.58 \pm 0.03$ & $0.56 \pm 0.03$ & $0.84 \pm 0.05$ & $0.98 \pm 0.04$ \\
\hline 32 & Sinapic acid derivative & - & $0.15 \pm 0.01$ & - & $0.12 \pm 0.01$ \\
\hline Total & & $4.9 \pm 0.2$ & $9.7 \pm 0.3$ & $8.0 \pm 0.2$ & $11.8 \pm 0.3$ \\
\hline \multicolumn{6}{|c|}{ Other compounds } \\
\hline 6 & Hydroxytyrosol-O-hexoside & $0.59 \pm 0.03$ & $0.25 \pm 0.01$ & $0.28 \pm 0.01$ & $0.24 \pm 0.01$ \\
\hline TIPC & & $24.1 \pm 0.5$ & $30.5 \pm 0.7$ & $14.5 \pm 0.2$ & $22.4 \pm 0.5$ \\
\hline
\end{tabular}

Values (mg/g DE) are mean \pm SD of three parallel measurements. TIPC: total individual phenolic content.

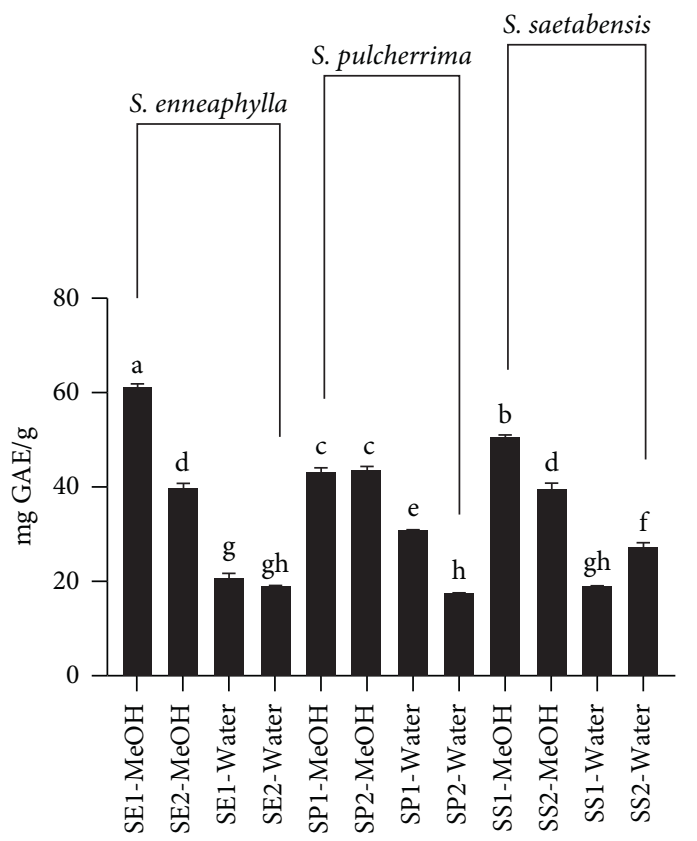

(a)

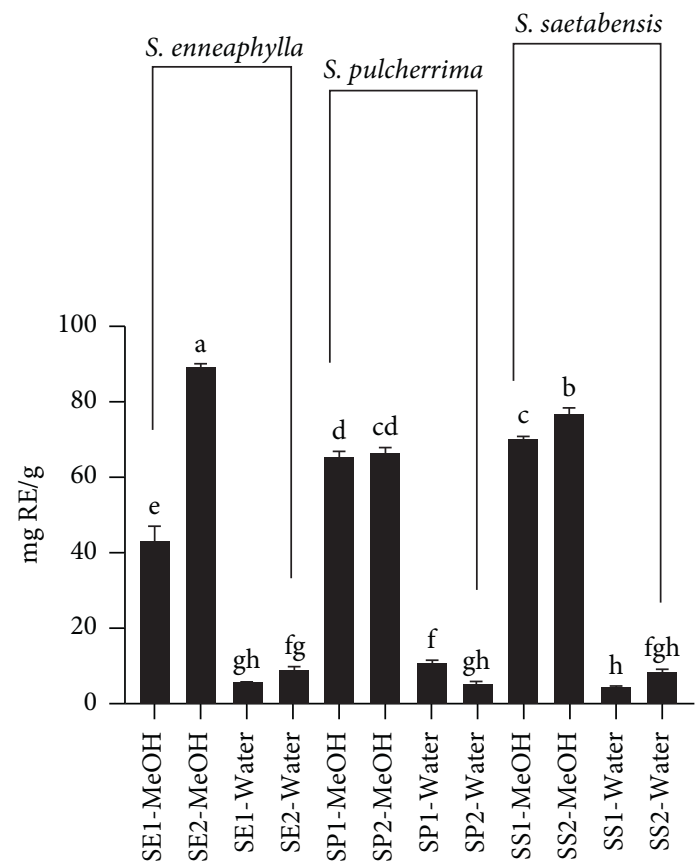

(b)

FIGURE 2: Total phenolic (a) and flavonoid (b) contents of the extracts by spectrophotometric assays. Values are expressed as mean \pm S.D. of three parallel measurements. GAE: gallic acid equivalents; RE: rutin equivalents. Different letters indicate significant differences in the extracts $(p<0.05)$. 
extracts. The best radical scavenging ability in DPPH and ABTS assays was obtained for the methanol extract of $S$. enneaphylla ( $89 \mathrm{mg} \mathrm{TE} / \mathrm{g}$ and $136 \mathrm{mg} \mathrm{TE} / \mathrm{g}$ ), followed by $S$. saetabensis $(75.3 \mathrm{mg} \mathrm{TE} / \mathrm{g}$ and $122 \mathrm{mg} \mathrm{TE} / \mathrm{g}$ ) and $S$. pulcherrima (66.8 $\mathrm{mg} \mathrm{TE} / \mathrm{g}$ and $105.3 \mathrm{mg} \mathrm{TE} / \mathrm{g}$ ). CUPRAC and FRAP assays include the transformation of $\mathrm{Cu}^{2+}$ to $\mathrm{Cu}^{+}$and $\mathrm{Fe}^{3+}$ to $\mathrm{Fe}^{2+}$, respectively. These transformations could be important to prevent Fenton or Haber-Weiss reactions and thus could stop the production of hydroxyl radicals. From this point of view, the tested Sarcocapnos extracts exhibited significant reduction ability. The highest abilities were recorded in S. enneaphylla and $S$. saetabansis methanol extracts, and they were statistically similar $(p>0.05)$. The results for phosphomolybdenum assay, which is based on the transformation of Mo (VI) to Mo (V), were similar to CUPRAC and FRAP, and again the highest ability was noted in S. enneaphylla with the value of $1.97 \mathrm{mmol} \mathrm{TE} / \mathrm{g}$. The results for radical scavenging and reducing power assays were in good agreement with the levels of total bioactive compounds. Our observations coincide with the previous studies, which found a good analogy between total bioactive compounds and antioxidant properties [30, 31]. Concerning metal chelating ability, the results are inconsistent with the other assays. Metal chelating abilities of the water extracts were found to outperform methanol extracts. This rather contradictory finding may be due to the presence of nonphenolic chelators in the water extracts $[32,33]$.

3.5. Enzyme Inhibition Properties. Several enzymes are targets to manage several diseases, and thus, the symptoms could be decreased by inhibiting these enzymes. Due to the side effects of synthetic compounds, researchers tend to focus on natural sources for the development of novel inhibitors with lower side effects [34-37]. Hence, we investigated the enzyme inhibitory effects of Sarcocapnos species against cholinesterases (AChE and BChE), tyrosinase, amylase, and glucosidase. The results are shown in Table 7. Except for glucosidase, all enzymes were inhibited by the tested extracts. Regarding AChE inhibition abilities, the values ranged from $2.7 \mathrm{mg} \mathrm{GALAE} / \mathrm{g}$ to $5.2 \mathrm{mg} \mathrm{GALAE} / \mathrm{g}$, while the values for $\mathrm{BChE}$ ranged from $10 \mathrm{mg}$ GALAE/g to $22.2 \mathrm{mg} \mathrm{GALAE} / \mathrm{g}$. These inhibition effects may be linked to the chemical profiles of the extracts. For example, the extracts contained some flavonoids such as rutin, isorhamnetin, or kaempferol, which have been previously reported as cholinesterase inhibitors [38-40]. Tyrosinase is a main enzyme in the melanogenesis pathway, and its inhibition is an important therapeutic way to control hyperpigmentation problems. As depicted in Table 7, the methanol extracts exhibited stronger tyrosinase inhibitor effects than water extracts. In the same way, we observed the highest inhibitor effects for methanol extracts against amylase and glucosidase. The tested water extracts were not active on glucosidase. These observations are consistent with the levels of total bioactive compounds. A similar linear correlation between total bioactive components and these inhibitions was reported by other authors [41-44]. In addition, some flavonoids (rutin, isorhamnetin, etc.) have been reported as significant inhibitors against these enzymes [45-48]. Taken together, the tested Sarcocapnos species can be appraised as sources of natural enzyme inhibitors to combat global health problems.

3.6. Multivariate Analysis. An unsupervised exploratory multivariate analysis PCA was performed on biological activities datasets of Sarcocapnos species extracts derived from two solvents with different geographical origins. The main focus of doing PCA was to comprehensively screen the differentially expressed biological activities between Sarcocapnos species samples. In fact, two independent factors were involved as follows: geographical origins and solvent used for extraction. Thus, through PCA, we sought to determine which factor was responsible to distinguish between the biological activities of the samples, previously uncovered by the univariate analysis.

Results are displayed in Figure 3. As seen in Figure 3(a), PC1 and PC2 together expressed a cumulative variance of $90.2 \%(\mathrm{PC} 1=80 \%, \mathrm{PC} 2=10.2 \%)$. The contribution of biological activities on both retained principal component is shown in Figure 3(b); as can be seen, eight biological activities represented the most associated variables with PC1 while only AChE was most closely linked with PC2. By observing the score plots reported in Figures 3(c) and 3(d), it could be noticed that the extracts can be classified in terms of different factors. Concerning Figure 3(c), extracts were separated into two groups along PC1, based on the solvent used for extraction. Therefore, the biological activities of studied species were affected by the varied polarity of both solvents used. Several reports highlighted the influence of the type of solvent on the biological activities of a large number of species $[31,49,50]$. This disparity reflects the availability of different bioactive compounds, involved in these biological activities, in each extraction solvent. As a result, selecting the appropriate solvent leads to a high recovery yield of molecules of biological interest.

Afterwards, by analyzing the score plots under another angle, the difference between the extracts of Sarcocapnos species can be also attributed to a geographical factor (Figure 3(d)). Nonetheless, this geographical factor took effect within methanolic extracts of species. Two subclusters were observed; indeed, samples obtained from specimens of Sarcocapnos species from Segura de la Sierra, Vilches, and Fuensanta de Martos, respectively, were distinguished from those harvested in Alcaudete, Jódar, and between Jaén and Otínar. On the other hand, as regards to the extracts derived from water, a difference was observed only between the samples of S. enneaphylla. In more detail, specimen from Vilches was detached from that of Alcaudete along PC1.

Heatmap and HCA were produced on the result of PCA taking into account only the first two principal components of PCA, for visualizing differential bioactivities in the 
TABLE 6: Antioxidant activities of the extracts of S. enneaphylla (SE), S. pulcherrima (SP), and S. saetabensis (SS), each one from two different locations, extracted in methanol and water.

\begin{tabular}{|c|c|c|c|c|c|c|c|c|}
\hline \multicolumn{3}{|c|}{ Samples } & $\begin{array}{c}\mathrm{DPPH} \\
(\mathrm{mg} \mathrm{TE} / \mathrm{g})\end{array}$ & $\begin{array}{c}\text { ABTS } \\
(\mathrm{mg} \mathrm{TE} / \mathrm{g})\end{array}$ & $\begin{array}{l}\text { CUPRAC } \\
(\mathrm{mg} \mathrm{TE} / \mathrm{g})\end{array}$ & $\begin{array}{c}\text { FRAP } \\
(\mathrm{mg} \mathrm{TE} / \mathrm{g})\end{array}$ & $\begin{array}{c}\text { Phosphomolybdenum } \\
\text { (mmol TE/g) }\end{array}$ & $\begin{array}{c}\text { Chelating activity } \\
\text { (mg EDTAE/g) }\end{array}$ \\
\hline \multirow{4}{*}{ S. enneaphylla } & \multirow{2}{*}{$\mathrm{MeOH}$} & SE1 & $89 \pm 1^{a}$ & $136 \pm 3^{a}$ & $289 \pm 9^{a}$ & $165 \pm 9^{a}$ & $1.97 \pm 0.02^{\mathrm{a}}$ & $28.3 \pm 0.5^{\mathrm{d}}$ \\
\hline & & SE2 & $60 \pm 1^{\mathrm{d}}$ & $95 \pm 4^{\mathrm{d}}$ & $182 \pm 3^{\mathrm{d}}$ & $101 \pm 1^{\mathrm{d}}$ & $1.26 \pm 0.06^{\mathrm{c}}$ & $28.2 \pm 0.7^{\mathrm{d}}$ \\
\hline & \multirow[b]{2}{*}{$\mathrm{H}_{2} \mathrm{O}$} & SE1 & $38.2 \pm 0.4^{\mathrm{f}}$ & $50.8 \pm 0.7^{\mathrm{fg}}$ & $76 \pm 2^{\mathrm{f}}$ & $61.1 \pm 0.9^{g}$ & $0.11 \pm 0.04^{\mathrm{gh}}$ & $64.3 \pm 0.3^{\mathrm{a}}$ \\
\hline & & SE2 & $36 \pm 1^{\mathrm{f}}$ & $46 \pm 2^{\mathrm{g}}$ & $66.9 \pm 0.8^{\mathrm{g}}$ & $75.2 \pm 0.4^{\mathrm{f}}$ & $0.35 \pm 0.01^{\mathrm{e}}$ & $62.3 \pm 0.9^{\mathrm{a}}$ \\
\hline \multirow{4}{*}{ S. pulcherrima } & \multirow{2}{*}{$\mathrm{MeOH}$} & SP1 & $66.8 \pm 0.6^{\mathrm{c}}$ & $105.3 \pm 0.7^{\mathrm{c}}$ & $199 \pm 6^{b}$ & $118 \pm 4^{\mathrm{c}}$ & $1.27 \pm 0.04^{\mathrm{c}}$ & $18.8 \pm 0.4^{\mathrm{f}}$ \\
\hline & & SP2 & $67 \pm 1^{c}$ & $107 \pm 2^{c}$ & $195 \pm 1^{b c}$ & $139 \pm 3^{b}$ & $1.63 \pm 0.01^{b}$ & $20 \pm 1^{\mathrm{ef}}$ \\
\hline & \multirow{2}{*}{$\mathrm{H}_{2} \mathrm{O}$} & SP1 & $48 \pm 1^{\mathrm{e}}$ & $92 \pm 3^{\mathrm{d}}$ & $98 \pm 2^{\mathrm{e}}$ & $89 \pm 3^{\mathrm{e}}$ & $0.23 \pm 0.04^{\mathrm{f}}$ & $56.9 \pm 0.2^{\mathrm{b}}$ \\
\hline & & SP2 & $26 \pm 2^{\mathrm{g}}$ & $51.2 \pm 0.6^{\mathrm{fg}}$ & $51.8 \pm 0.2^{\mathrm{h}}$ & $44.7 \pm 0.3^{\mathrm{h}}$ & $0.03 \pm 0.01^{\mathrm{h}}$ & $36 \pm 4^{c}$ \\
\hline \multirow{4}{*}{ S. saetabensis } & \multirow{2}{*}{$\mathrm{MeOH}$} & SS1 & $75.3 \pm 0.6^{\mathrm{b}}$ & $122 \pm 3^{b}$ & $288.3 \pm 0.8^{\mathrm{a}}$ & $165.7 \pm 0.7^{\mathrm{a}}$ & $1.59 \pm 0.04^{\mathrm{b}}$ & $24 \pm 3^{\mathrm{de}}$ \\
\hline & & SS2 & $69 \pm 1^{c}$ & $112 \pm 0.9^{c}$ & $187.5 \pm 0.6^{\mathrm{cd}}$ & $105 \pm 3^{\mathrm{d}}$ & $1.11 \pm 0.01^{\mathrm{d}}$ & $55 \pm 2^{\mathrm{b}}$ \\
\hline & \multirow{2}{*}{$\mathrm{H}_{2} \mathrm{O}$} & SS1 & $37.9 \pm 0.6^{\mathrm{f}}$ & $56 \pm 3^{\mathrm{f}}$ & $59.2 \pm 0.5^{\mathrm{gh}}$ & $53.3 \pm 0.2^{\mathrm{gh}}$ & $0.12 \pm 0.03^{\mathrm{gh}}$ & $62.7 \pm 0.2^{\mathrm{a}}$ \\
\hline & & SS2 & $49.2 \pm 0.8^{\mathrm{e}}$ & $66 \pm 1^{\mathrm{e}}$ & $95 \pm 1^{\mathrm{e}}$ & $80 \pm 0.6^{\mathrm{ef}}$ & $0.16 \pm 0.04^{\mathrm{fg}}$ & $65.9 \pm 0.6^{\mathrm{a}}$ \\
\hline
\end{tabular}

Values expressed are means \pm S.D. of three parallel measurements; TE: Trolox equivalent; EDTAE: EDTA equivalent. Different letters indicate significant differences in the extracts $(p<0.05)$.

TABLE 7: Enzyme inhibitory properties of the extracts of S. enneaphylla (SE), S. pulcherrima (SP), and S. saetabensis (SS), each one from two different locations, extracted in methanol and water.

\begin{tabular}{|c|c|c|c|c|c|c|c|}
\hline \multicolumn{3}{|c|}{ Samples } & $\begin{array}{l}\text { AChE inhibition } \\
\text { (mg GALAE/g) }\end{array}$ & $\begin{array}{l}\text { BChE inhibition } \\
\text { (mg GALAE/g) }\end{array}$ & $\begin{array}{l}\text { Tyrosinase inhibition } \\
\text { (mg KAE/g) }\end{array}$ & $\begin{array}{c}\text { Amylase inhibition } \\
\text { (mmol ACAE/g) }\end{array}$ & $\begin{array}{l}\text { Glucosidase inhibition } \\
\text { (mmol ACAE/g) }\end{array}$ \\
\hline \multirow{4}{*}{ S. enneaphylla } & $\mathrm{MeOH}$ & SE1 & $3.50 \pm 0.03^{\mathrm{d}}$ & $20.8 \pm 0.9^{\mathrm{abc}}$ & $143 \pm 3^{\mathrm{a}}$ & $0.61 \pm 0.03^{\mathrm{a}}$ & $2.82 \pm 0.01^{\mathrm{ab}}$ \\
\hline & & SE2 & $4.5 \pm 0.4^{\mathrm{c}}$ & $20.8 \pm 0.3^{\mathrm{abc}}$ & $140.5 \pm 0.2^{\mathrm{a}}$ & $0.55 \pm 0.03^{\mathrm{ab}}$ & $3.11 \pm 0.03^{\mathrm{a}}$ \\
\hline & $\mathrm{H} 2 \mathrm{O}$ & SE1 & $3.6 \pm 0.2^{\mathrm{d}}$ & $13 \pm 2^{\mathrm{fg}}$ & $42 \pm 5^{\mathrm{c}}$ & $0.08 \pm 0.01^{\mathrm{c}}$ & na \\
\hline & & SE2 & $4.18 \pm 0.07^{\mathrm{c}}$ & $16 \pm 1^{\mathrm{def}}$ & $43 \pm 3^{c}$ & $0.08 \pm 0.01^{\mathrm{c}}$ & na \\
\hline \multirow{4}{*}{ S. pulcherrima } & $\mathrm{MeOH}$ & SP1 & $4.97 \pm 0.07^{\mathrm{ab}}$ & $21.7 \pm 0.8^{\mathrm{ab}}$ & $140 \pm 3^{\mathrm{a}}$ & $0.51 \pm 0.01^{\mathrm{b}}$ & $2.1 \pm 0.3^{\mathrm{c}}$ \\
\hline & & SP2 & $3.2 \pm 0.1^{\mathrm{d}}$ & $22.0 \pm 0.6^{\mathrm{ab}}$ & $142.46 \pm 0.08^{\mathrm{a}}$ & $0.57 \pm 0.04^{\mathrm{ab}}$ & $2.5 \pm 0.2^{\mathrm{b}}$ \\
\hline & $\mathrm{H} 2 \mathrm{O}$ & SP1 & $2.7 \pm 0.2^{\mathrm{e}}$ & $17.3 \pm 0.8^{\text {cdef }}$ & $57 \pm 5^{\mathrm{b}}$ & $0.10 \pm 0.01^{\mathrm{c}}$ & na \\
\hline & & SP2 & $3.28 \pm 0.04^{\mathrm{d}}$ & $10 \pm 3^{\mathrm{g}}$ & $39 \pm 2^{c}$ & $0.09 \pm 0.01^{\mathrm{c}}$ & na \\
\hline \multirow{4}{*}{ S. saetabensis } & $\mathrm{MeOH}$ & SS1 & $4.19 \pm 0.01^{\mathrm{c}}$ & $22.2 \pm 0.2^{\mathrm{a}}$ & $144.2 \pm 0.8^{\mathrm{a}}$ & $0.59 \pm 0.06^{\mathrm{a}}$ & $2.87 \pm 0.01^{\mathrm{ab}}$ \\
\hline & & SS2 & $5.2 \pm 0.3^{\mathrm{a}}$ & $20 \pm 2^{\mathrm{abcd}}$ & $142.2 \pm 0.8^{\mathrm{a}}$ & $0.59 \pm 0.01^{\mathrm{a}}$ & $2.1 \pm 0.2^{c}$ \\
\hline & $\mathrm{H} 2 \mathrm{O}$ & SS1 & $4.64 \pm 0.07^{\mathrm{bc}}$ & $15 \pm 1^{\mathrm{ef}}$ & $44 \pm 3^{c}$ & $0.08 \pm 0.01^{\mathrm{c}}$ & na \\
\hline & & SS2 & $4.60 \pm 0.07^{\mathrm{bc}}$ & $18 \pm 1^{\text {bcde }}$ & $46.2 \pm 0.7^{\mathrm{c}}$ & $0.08 \pm 0.01^{c}$ & na \\
\hline
\end{tabular}

Values expressed are mean \pm S.D. of three parallel measurements; AChE: acetylcholinesterase; BChE: butyrylcholinesterase; GALAE: galantamine equivalent; KAE: kojic acid equivalent; ACAE: acarbose equivalent; na: not active. Different letters indicate significant differences in the extracts $(p<0.05)$.
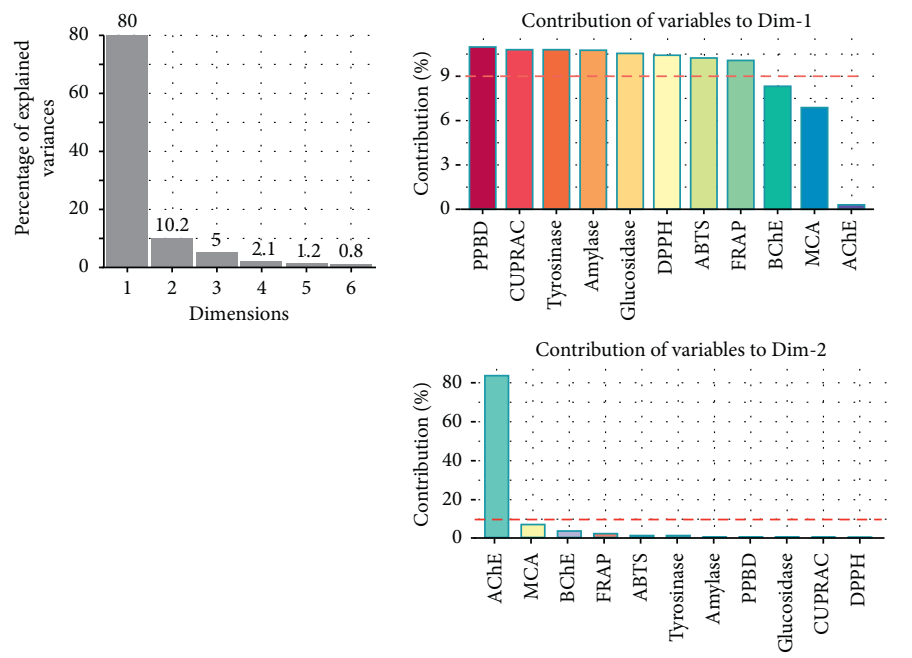

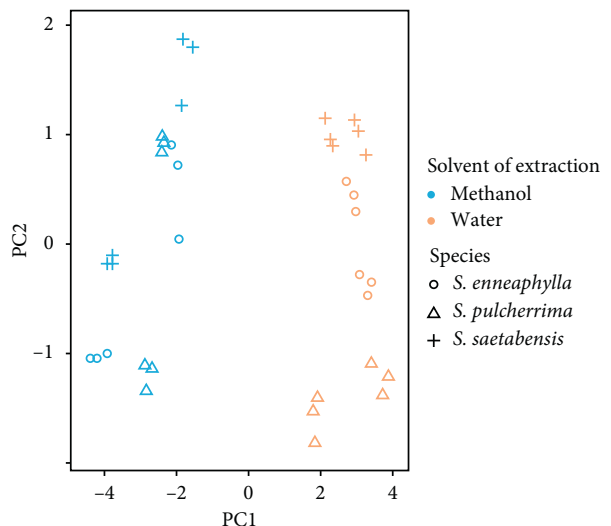

(c) (b)

(a)

FIgURE 3: Continued. 


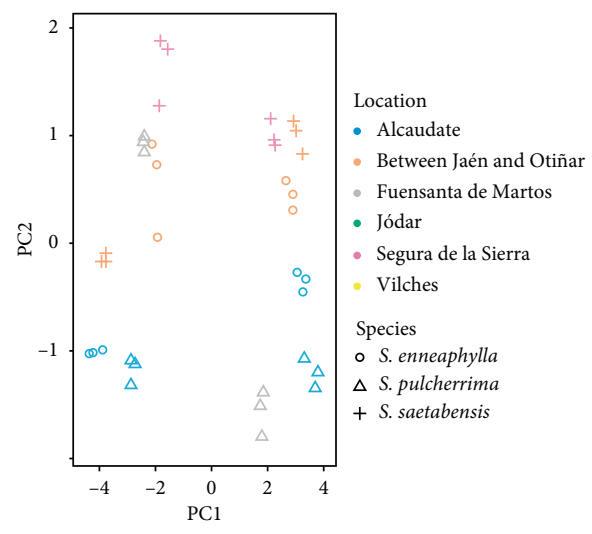

(d)

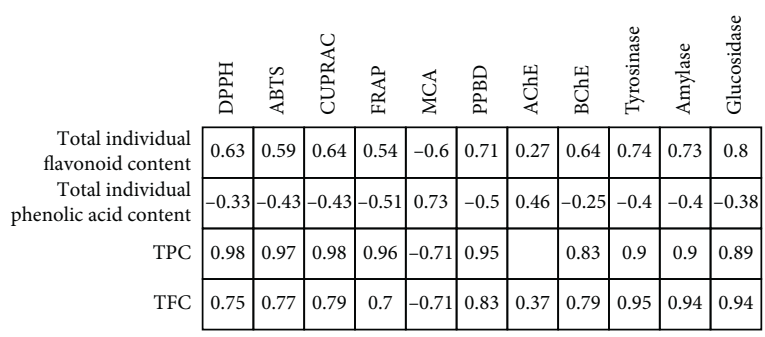

(e)

Figure 3: Principal component analysis of Sarcocapnos species based on biological activities profiling. (a) Percentage of variance explained by each principal component. (b) Relation between biological activities and the principal component. (c, d) Score plot representing samples in the space PC1 vs PC2 in terms of extractive solvent and geographical origins, respectively. (e) Correlation between phenolic/flavonoid contents and biological activities.

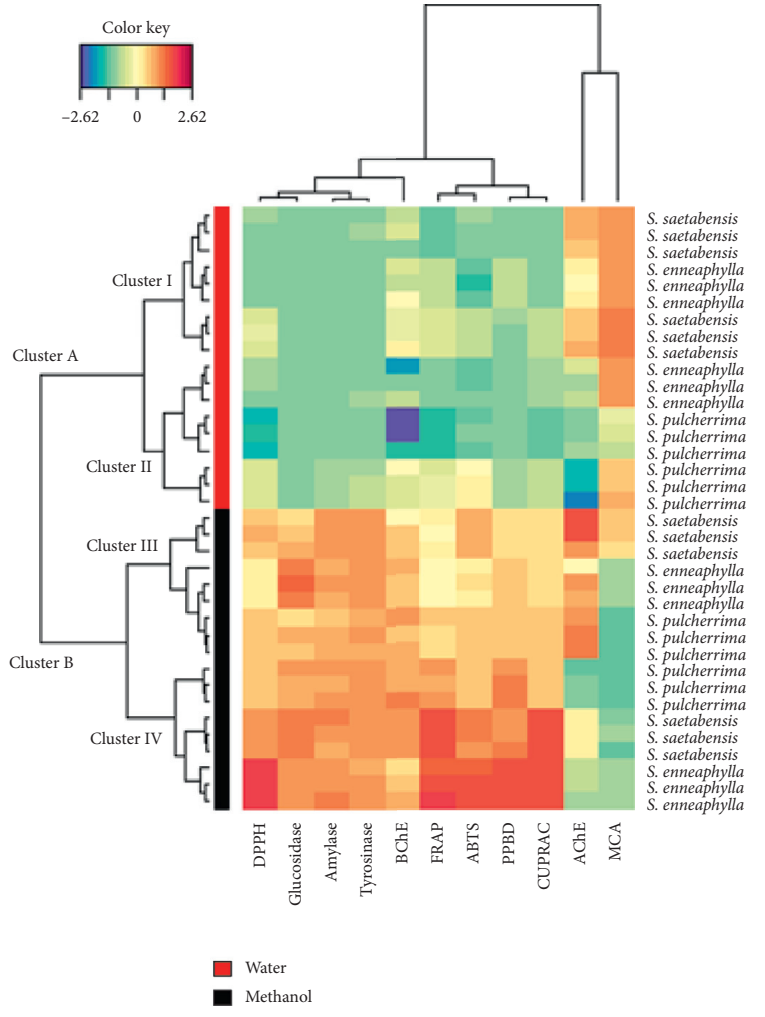

(a)

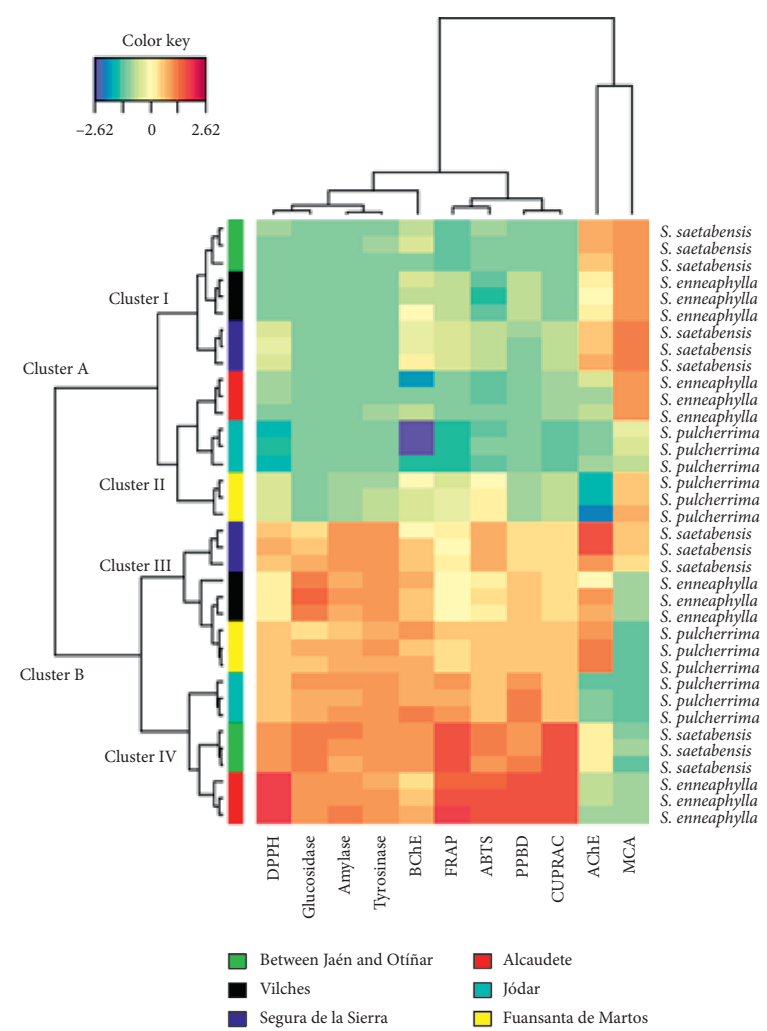

(b)

FIgUre 4: Heatmap and HCA analyses on biological activities of Sarcocapnos species built up from PCA result. (a) Clustering in relation to extractive solvent. (b) Clustering in relation to geographical origin. Red color: strong activity. Blue color: low activity.

different samples (Figure 4). Two major clusters and their respective two subclusters were obtained (Figure 4(a)). As can be seen, methanol extracts of all studied Sarcocapnos species were found to be more active against the vast majority of the evaluated biological activities, due to the higher solubility of the bioactive compounds in methanol.

The highest values of total phenolic and total flavonoid contents (spectrophotometric analyses), as well as total individual contents (HPLC-MS), were obtained with extracts derived from methanol for all species. Hence, TPC, TFC, and total individual flavonoids content correlated very well with all biological activities except AChE and MCA (Figure 3(e)). In particular, the total antioxidant activity from DPPH $(R=0.75 ; 0.98$; and 0.63$)$, ABTS $(R=0.77 ; 0.97$; and 0.59$)$, FRAP $(R=0.7 ; 0.96 ; 0.54)$, CUPRAC $(R=0.79$; $0.98 ; 0.64)$, and $\operatorname{PPBD}(R=083 ; 0.95 ; 0.71)$ assays was 
positively linked with TFC, TPC, and total individual flavonoid content, respectively, while MCA assay was positively bound to total individual phenolic acid content $(R=0.93)$ at $p<0.05$. Additionally, the inhibition of tyrosinase, amylase, glucosidase, and $\mathrm{BChE}$ was highest with the increasing content of TFC $(R=0.95 ; 0.94 ; 094$; and 0.79$)$, TPC $(R=0.9 ; 0.9 ; 0.89 ; 0.93)$ and total individual flavonoids content $(R=0.74 ; 0.73 ; 0.8 ; 0.64)$ respectively. According to the literature, phenolic compounds (including the flavonoids), ubiquitous in plants, are of great interest due to their considerable beneficial for human health, since they prove to be able to cut down the incidence of several chronic ailments such as diabetes and Alzheimer and skin diseases through their antioxidant properties. Instead, their antioxidant activities are strongly linked with their structure, especially the position and number of the hydroxyl groups, the conjugated double bonds, and the nature of substitutions on the aromatic rings.

Afterwards, by analyzing the score plots under another angle, the difference between the extracts of Sarcocapnos species can be also attributed to a geographical factor (Figure 3(d)). Nonetheless, this geographical factor took effect within methanolic extracts of species. Two subclusters were observed; indeed, samples obtained from specimens of Sarcocapnos species from Segura de la Sierra, Vilches, and Fuensanta de Martos, respectively, were distinguished from those harvested in Alcaudete, Jódar, and between Jaén and Otíñar. On the other hand, as regards the extracts derived from water, a difference was observed only between the samples of S. enneaphylla. In more detail, specimen from Vilches was detached from that of Alcaudete along PC1.

Regarding Figure 4(b), the difference across subclusters III and IV as well as between S. enneaphylla specimens was found tangibly with AChE inhibition assay. As it happens, the highest activity was obtained within cluster III and $S$. enneaphylla specimen from Vilches (belonging the cluster I), respectively.

With regard to our results, the biological activities of studied species varied among the geographical origins. This observation is closely linked to the presence/absence of some key bioactive compounds under the influence of the variation of climatic conditions as well as the soil nutrient composition. This is in agreement with the report of Rocchetti [51], who underlined the impact of different geographical origins on phenolic composition of chardonnay wines.

\section{Conclusion}

In this work, we have presented the first report on the phenolic composition of three Sarcocapnos species as well as the relation with the bioactive properties. For the three species, methanol was the most suitable solvent, and the highest phenolic content as well as the highest bioactivities were found in extracts from S. enneaphylla, although the other species were also active in all the assays. Flavonoids were the most abundant compounds, followed by phenolic acids. Among flavonoids, rutin, kaempferol, and isorhamnetin glycosides were the main compounds. These compounds have been previously reported to present significant bioactivity and, thus, may be the main contributors to the observed effects. Multivariate analysis confirmed the relationship between phenolics concentration and bioactivity. It also indicated a clear difference within the same species depending on the geographical origin. The results here presented may open new ways to valorize Sarcocapnos species as sources of natural compounds for the food (nutraceuticals or food supplements) or pharmaceutical industry and represent a starting point for additional research, being the final goal the industrial applications of Sarcocapnos species.

\section{Data Availability}

The data used to support the findings of this study are included within the article.

\section{Conflicts of Interest}

The authors declare that they have no conflicts to interest.

\section{Acknowledgments}

Technical and human support provided by CICT of the Universidad de Jaén (UJA, MINECO, Junta de Andalucía, FEDER) is gratefully acknowledged. Junta de Andalucía (Jaén Province Delegation) is acknowledged for granting us permission for collecting samples. Vytrus Biotech is also gratefully acknowledged due to the contract 3050 Vytrus Biotech-UJA for the conservation of Sarcocapnos species.

\section{Supplementary Materials}

File S1: chemicals and reagents. File S2: HPLC analysis conditions. File S3: assays for total phenolic and flavonoid contents. File S4: determination of antioxidant and enzyme inhibitory effects. Table S1: total phenolic and flavonoid contents of the extracts of S. enneaphylla (SE), S. pulcherrima (SP), and S. saetabensis (SS), each one from two different locations, extracted in methanol and water. Figure S1: HPLC-ESI/MS $^{\mathrm{n}}$ base peak chromatograms (BPC) of the aqueous extracts of (A) S. enneaphylla (SE1), (B) S. pulcherrima (SP1), and (C) S. saetabensis (SS2). Figure S2: ranges of flavonoids, phenolic acids, and TIPC values for the three Sarcocapnos species. Figure S3: total individual phenolic content (A), total flavonoid content (B), and phenolic acid content $(C)$ of the extracts by HPLC-DAD quantification. Different letters indicate significant differences in the extracts $(p<0.05)$. (Supplementary Materials)

\section{References}

[1] C. J. Dillard and J. B. German, "Phytochemicals: nutraceuticals and human health," Journal of the Science of Food and Agriculture, vol. 80, no. 12, pp. 1744-1756, 2000.

[2] H. P. S. Makkar, G. Francis, and K. Becker, "Bioactivity of phytochemicals in some lesser-known plants and their effects and potential applications in livestock and aquaculture production systems," Animal, vol. 1, no. 9, pp. 1371-1391, 2007. 
[3] M. Chambouleyron, M. Bidat, and J.-F. Léger, "Sarcocapnos crassifoliasubsp.simplicifolia (papaveraceae, fumarioideae), a new narrow-endemic taxon from northeastern Morocco," Annales Botanici Fennici, vol. 52, no. 3-4, pp. 205-210, 2015.

[4] M. J. Salinas, C. Ruiz-Rejon, C. Morales et al., "Contribution to the taxonomy and phylogeny of Sarcocapnos DC. (Fumariaceae)," Plant Systematics and Evolution, vol. 237, no. 3-4, pp. 153-164, 2003.

[5] M. A. Pérez-Gutiérrez, V. N. Suárez-Santiago, I. López-Flores, A. T. Romero, and M. A. Garrido-Ramos, "Concerted evolution of satellite DNA in Sarcocapnos: a matter of time," Plant Molecular Biology, vol. 78, no. 1-2, pp. 19-29, 2012.

[6] M. J. Salinas and D. C. Sarcocapnos, "Claves de la Flora Vascular de Andalucía Oriental," Edited by G. Blanca, B. Cabezudo, M. Cueto, C. Morales Torres, and C. Salazar, Eds., pp. 461-462, Servicios de Publicaciones de las Universidades de Granada, Almería, Spain, 2011.

[7] B. Cabezudo, S. Talavera, G. Blanca et al., Lista roja de la Flora Vascular de Andalucía; Consejería de Medio Ambiente, Junta de Andalucía, Seville, Spain, 2005.

[8] E. Tojo, D. Dominguez, and L. Castedo, "Alkaloids from Sarcocapnos enneaphylla," Phytochemistry, vol. 30, no. 3, pp. 1005-1010, 1991.

[9] R. Suau, B. Cabezudo, M. Valpuesta, N. Posadas, A. Diaz, and G. Torres, "Identification and quantification of isoquinoline alkaloids in the genusSarcocapnos by GC-MS," Phytochemical Analysis, vol. 16, no. 5, pp. 322-327, 2005.

[10] S. López, E. Tojo, O. Blanco, M. C. Villaverde, and L. Castedo, "Alkaloids from Spanish Sarcocapnos species," Phytochemistry, vol. 30, no. 4, pp. 1175-1182, 1991.

[11] M. Lidén and D. C. Sarcocapnos, Flora Iberica: Plantas vasculares de la Península Ibérica e Islas Baleares, S. Castroviejo, Ed., vol. 1, pp. 433-438, CSIC, Madrid, Spain, 1986.

[12] C. Morales and A. T. Romero-Garcia, "A new species of the genusSarcocapnos (Fumariaceae) from eastern Andalusia (Spain)," Plant Systematics and Evolution, vol. 177, no. 1-2, pp. 1-10, 1991.

[13] G. Mateo and R. Figuerola, Flora analítica de la provincia de Valencia; Alfons el Magnànim, Institució Valenciana d'Estudisi Investigació, Valencia, Spain, 1987.

[14] O. Blanco, L. Castedo, D. Cortes, and M. Carmen Villaverde, "Alkaloids from Sarcocapnos saetabensis," Phytochemistry, vol. 30, no. 6, pp. 2071-2074, 1991.

[15] S. Uysal, G. Zengin, M. Locatelli et al., "Cytotoxic and enzyme inhibitory potential of two Potentilla species (P. speciosa L. and $P$. reptans Willd.) and their chemical composition," Frontiers in Pharmacology, vol. 8, p. 290, 2017.

[16] D. M. Grochowski, S. Uysal, A. Aktumsek et al., "In vitro enzyme inhibitory properties, antioxidant activities, and phytochemical profile of Potentilla thuringiaca," Phytochemistry Letters, vol. 20, pp. 365-372, 2017.

[17] M. N. Clifford, K. L. Johnston, S. Knight, and N. Kuhnert, "Hierarchical scheme for LC-MSnIdentification of chlorogenic acids," Journal of Agricultural and Food Chemistry, vol. 51, no. 10, pp. 2900-2911, 2003.

[18] S. I. Falcão, M. Vilas-Boas, L. M. Estevinho, C. Barros, M. R. M. Domingues, and S. M. Cardoso, "Phenolic characterization of Northeast Portuguese propolis: usual and unusual compounds," Analytical and Bioanalytical Chemistry, vol. 396, no. 2, pp. 887-897, 2010.

[19] C. B. Steingass, M. P. Glock, R. M. Schweiggert, and R. Carle, "Studies into the phenolic patterns of different tissues of pineapple (Ananas comosus [L.] Merr.) infructescence by
HPLC-DAD-ESI-MS n and GC-MS analysis," Analytical and Bioanalytical Chemistry, vol. 407, no. 21, pp. 6463-6479, 2015.

[20] M. P. Fernández-Poyatos, A. Ruiz-Medina, and E. J. LlorentMartínez, "Phytochemical profile, mineral content, and antioxidant activity of Olea europaea L. cv. Cornezuelo table olives. Influence of in vitro simulated gastrointestinal digestion," Food Chemistry, vol. 297, p. 124933, 2019.

[21] V. Spínola, E. J. Llorent-Martínez, S. Gouveia, and P. C. Castilho, "Myrica faya: a new source of antioxidant phytochemicals," Journal of Agricultural and Food Chemistry, vol. 62, no. 40, pp. 9722-9735, 2014.

[22] X. Tian, Z. Li, Y. Lin, M. Chen, G. Pan, and C. Huang, "Study on the PK profiles of magnoflorine and its potential interaction in Cortex phellodendri decoction by LC-MS/MS," Analytical and Bioanalytical Chemistry, vol. 406, no. 3, pp. 841-849, 2014.

[23] M. Affes, J. Fakhfakh, I. Daoud et al., "UHPLC/HR-ESI-MS/ MS profiling of phenolics from Tunisian Lycium arabicum Boiss. Antioxidant and anti-lipase activities' evaluation," Chemistry \& Biodiversity, vol. 14, no. 9, Article ID e1700095, 2017.

[24] L. Van Hoyweghen, K. De Bosscher, G. Haegeman, D. Deforce, and A. Heyerick, "In VitroInhibition of the transcription factor NF- $\kappa \mathrm{B}$ and cyclooxygenase by bamboo extracts," Phytotherapy Research, vol. 28, no. 2, pp. 224-230, 2014.

[25] L. S. Olegário, J. K. S. Andrade, G. R. S. Andrade et al., "Chemical characterization of four Brazilian brown propolis: an insight in tracking of its geographical location of production and quality control," Food Research International, vol. 123, pp. 481-502, 2019.

[26] C. L. Dittgen, J. F. Hoffmann, F. C. Chaves, C. V. Rombaldi, J. M. C. Filho, and N. L. Vanier, "Discrimination of genotype and geographical origin of black rice grown in Brazil by LCMS analysis of phenolics," Food Chemistry, vol. 288, pp. 297-305, 2019.

[27] I. G. Mekinić, I. Ljubenkov, S. Smole Možina et al., "Abiotic factors during a one-year vegetation period affect sage phenolic metabolites, antioxidants and antimicrobials," Industrial Crops and Products, vol. 141, Article ID 111741, 2019.

[28] Y. El Atki, I. Aouam, F. El kamari et al., "Total phenolic and flavonoid contents and antioxidant activities of extracts from Teucrium polium growing wild in Morocco," Materials Today: Proceedings, vol. 13, no. 3, pp. 777-783, 2019.

[29] A. Gasmi, M. A. Benabderrahim, F. Guasmi et al., "Phenolic profiling, sugar composition and antioxidant capacity of arta (Calligonum comosum L.), a wild Tunisian desert plant," Industrial Crops and Products, vol. 130, pp. 436-442, 2019.

[30] M. Yang, Y. Ma, Z. Wang et al., "Phenolic constituents, antioxidant and cytoprotective activities of crude extract and fractions from cultivated artichoke inflorescence," Industrial Crops and Products, vol. 143, Article ID 111433, 2020.

[31] B. B. Ismail, Y. Pu, M. Guo, X. Ma, and D. Liu, "LC-MS/QTOF identification of phytochemicals and the effects of solvents on phenolic constituents and antioxidant activity of baobab (Adansonia digitata) fruit pulp," Food Chemistry, vol. 277, pp. 279-288, 2019.

[32] M. F. Mahomoodally, G. Zengin, D. Zheleva-Dimitrova et al., "Metabolomics profiling, bio-pharmaceutical properties of Hypericum lanuginosum extracts by in vitro and in silico approaches," Industrial Crops and Products, vol. 133, pp. 373-382, 2019.

[33] R. G. O. Rumbaoa, D. F. Cornago, and I. M. Geronimo, "Phenolic content and antioxidant capacity of Philippine 
potato (Solanum tuberosum) tubers," Journal of Food Composition and Analysis, vol. 22, no. 6, pp. 546-550, 2009.

[34] A. De Simone, M. Naldi, D. Tedesco, M. Bartolini, L. Davani, and V. Andrisano, "Advanced analytical methodologies in Alzheimer's disease drug discovery," Journal of Pharmaceutical and Biomedical Analysis, vol. 178, p. 112899, 2020.

[35] P. Mishra, A. Kumar, and G. Panda, "Anti-cholinesterase hybrids as multi-target-directed ligands against Alzheimer's disease (1998-2018)," Bioorganic \& Medicinal Chemistry, vol. 27, no. 6, pp. 895-930, 2019.

[36] R. Tundis, M. R. Loizzo, and F. Menichini, "Natural products as $\alpha$-amylase and $\alpha$-glucosidase inhibitors and their hypoglycaemic potential in the treatment of diabetes: an update," Mini-Reviews in Medicinal Chemistry, vol. 10, no. 4, pp. 315-331, 2010.

[37] J. M. Barbosa Filho, K. C. P. Medeiros, M. d. F. F. M. Diniz et al., "Natural products inhibitors of the enzyme acetylcholinesterase," Revista Brasileira de Farmacognosia, vol. 16, no. 2, pp. 258-285, 2006.

[38] A. O. Ademosun, G. Oboh, F. Bello, and P. O. Ayeni, "Antioxidative properties and effect of quercetin and its glycosylated form (rutin) on acetylcholinesterase and butyrylcholinesterase activities," Journal of Evidence-Based Complementary \& Alternative Medicine, vol. 21, no. 4, pp. NP11-NP17, 2016.

[39] M. T. H. Khan, I. Orhan, F. S. Şenol et al., "Cholinesterase inhibitory activities of some flavonoid derivatives and chosen xanthone and their molecular docking studies," ChemicoBiological Interactions, vol. 181, no. 3, pp. 383-389, 2009.

[40] D. N. Olennikov, N. I. Kashchenko, N. K. Chirikova, A. Akobirshoeva, I. N. Zilfikarov, and C. Vennos, "Isorhamnetin and quercetin derivatives as anti-acetylcholinesterase principles of marigold (Calendula officinalis) flowers and preparations," International Journal of Molecular Sciences, vol. 18, no. 8, p. E1685, 2017.

[41] P. Jiang, J. Xiong, F. Wang, M. H. Grace, M. A. Lila, and R. Xu, " $\alpha$-Amylase and $\alpha$-glucosidase inhibitory activities of phenolic extracts from Eucalyptus grandis $\times$ E. urophylla Bark," Journal of Chemistry, vol. 2017, Article ID 8516964, 7 pages, 2017.

[42] Z. H. Rana, M. K. Alam, and M. Akhtaruzzaman, "Nutritional composition, total phenolic content, antioxidant and $\alpha$-amylase inhibitory activities of different fractions of selected wild edible plants," Antioxidants, vol. 8, no. 7, p. 203, 2019.

[43] A. Jdey, H. Falleh, S. Ben Jannet et al., "Phytochemical investigation and antioxidant, antibacterial and anti-tyrosinase performances of six medicinal halophytes," South African Journal of Botany, vol. 112, pp. 508-514, 2017.

[44] A. M. Muddathir, K. Yamauchi, I. Batubara, E. A. M. Mohieldin, and T. Mitsunaga, "Anti-tyrosinase, total phenolic content and antioxidant activity of selected Sudanese medicinal plants," South African Journal of Botany, vol. 109, pp. 9-15, 2017.

[45] D. S. Metibemu, J. A. Saliu, A. O. Metibemu et al., "Molecular docking studies of isorhamnetin from Corchorus olitorius with target alpha-amylase related to Type 2 diabetes," Journal of Chemical and Pharmaceutical Research, vol. 8, no. 4, pp. 1262-1266, 2016.

[46] Y.-X. Si, Z.-J. Wang, D. Park et al., "Effects of isorhamnetin on tyrosinase: inhibition kinetics and computational simulation," Bioscience, Biotechnology, and Biochemistry, vol. 76, no. 6, pp. 1091-1097, 2012.

[47] A. I. Martinez-Gonzalez, Á. G. Díaz-Sánchez, L. A. de la Rosa, I. Bustos-Jaimes, and E. Alvarez-Parrilla, "Inhibition of $\alpha$-amylase by flavonoids: structure activity relationship (SAR)," Spectrochimica Acta Part A: Molecular and Biomolecular Spectroscopy, vol. 206, pp. 437-447, 2019.

[48] Y.-X. Si, S.-J. Yin, S. Oh et al., "An integrated study of tyrosinase inhibition by rutin: progress using a computational simulation," Journal of Biomolecular Structure and Dynamics, vol. 29, no. 5, pp. 999-1012, 2012.

[49] M. Abolmaesoomi, A. Abdul Aziz, S. Mat Junit, and J. Mohd Ali, "Ficus deltoidea: effects of solvent polarity on antioxidant and anti-proliferative activities in breast and colon cancer cells," European Journal of Integrative Medicine, vol. 28, pp. 57-67, 2019.

[50] R. Venkatachalam, K. Kalimuthu, V. Chinnadurai et al., "Various solvent effects on phytochemical constituent profiles, analysis of antioxidant and antidiabetic activities of Hopea parviflora," Process Biochemistry, vol. 89, pp. 227-232, 2020.

[51] G. Rocchetti, M. Gatti, L. Bavaresco, and L. Lucini, "Untargeted metabolomics to investigate the phenolic composition of Chardonnay wines from different origins," Journal of Food Composition and Analysis, vol. 71, pp. 87-93, 2018. 